\title{
RECURRENCE OF INGUINAL HERNIA IN GENERAL AND HERNIA SPECIALTY HOSPITALS IN ONTARIO, CANADA
}

\author{
by
}

\author{
Atiqa Malik
}

A thesis submitted in conformity with the requirements for the degree of Master of Science Institute of Medical Science

University of Toronto

(C) Copyright by Atiqa Malik, 2012 


\section{THESIS ABSTRACT}

Thesis Title: Recurrence of Inguinal Hernia in General and Hernia Specialty Hospitals in Ontario, Canada

Degree and Year of Convocation: Master of Science, 2012

Student: Atiqa Malik

Graduate Department: Institute of Medical Science

University: University of Toronto

\section{BACKGROUND:}

We compared hernia recurrence rates in patients undergoing primary elective inguinal hernia repair at general hospitals with the Shouldice Hospital in Ontario, Canada.

\section{METHODS:}

We conducted an administrative data analysis of persons who underwent inguinal hernia repair in Ontario, Canada from 1993-2007. Risk of recurrent hernia repair was estimated according to hospital type and volume, using Cox proportional-hazards regression models.

\section{RESULTS:}

Recurrence risk in the lowest volume quartile was $5.7 \%$, compared to $3.9 \%$ at high volume general hospitals and $1.1 \%$ at the Shouldice hospital. Compared to persons who had surgery at the lowest volume hospitals, hernia recurrence among Shouldice Hospital patients was 
substantially lower after adjustment for confounding variables (hazard ratio $0.18, \mathrm{CI}(0.16$ to $0.19), \mathrm{P}<0.001)$.

\section{CONCLUSIONS:}

Persons who had elective primary inguinal hernia repair at the Shouldice Hospital had a substantially lower risk of recurrence than those treated at general hospitals, including high volume general hospitals. 


\section{ACKNOWLEDGEMENTS}

There are a number of people I would like to thank for their contributions and guidance during the past two years, during which I have learnt so much:

Foremost, to Dr. David Urbach, my supervisor and mentor during my MSc degree; thank you for believing in me and providing me with so many wonderful opportunities. Your unwavering support, continuous mentorship and zeal for research has inspired and encouraged me. I will always be grateful to you for all the experiences and accomplishments I will be able to look back on, as they were all largely due to your unparalleled mentorship.

I would also like to thank my Program Advisory Committee members, Dr. Chaim Bell and Dr. Therese Stukel, for providing valuable guidance and input at every stage. I was honoured to work alongside the best and brightest at the Institute of Clinical and Evaluative Sciences, and would like to thank Longdi Fu in particular, for all his hard work and diligence, and for being so accommodating whenever I needed help.

Thank you to the members of the Institute of Medical Science, and the coordinators within the Clinical Decision Making and Health Care Division at Toronto General Hospital, who provide so much support to their students, and to my fellow students and colleagues for all their advice and support.

Finally, I will always be grateful to my family and friends who gave me courage every step of the way. I could not have come this far without the inspiration I gain everyday from the memories of my late father, and without the love and support of my mother, who deserves more credit than I do for all my accomplishments; thank you. 


\section{TABLE OF CONTENTS}

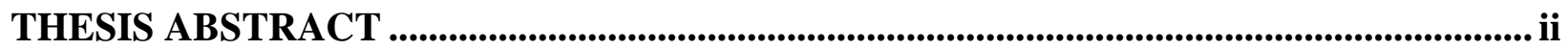

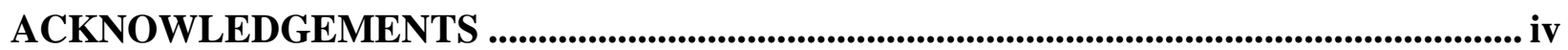

LIST OF TABLES .................................................................................................................................. viii

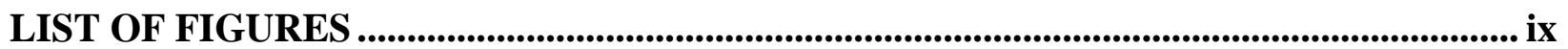

CHAPTER 1: BACKGROUND ............................................................................................ 1

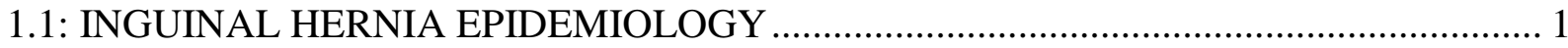

1.2: MANAGEMENT/REPAIR OF INGUINAL HERNIAS …................................................. 2

Anatomy/Origin of Groin Hernias ...................................................................................... 2

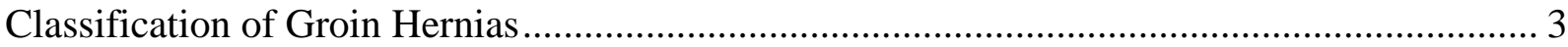

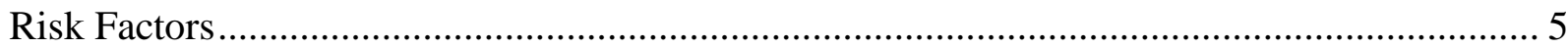

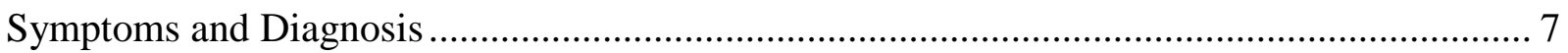

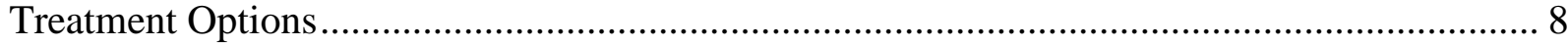

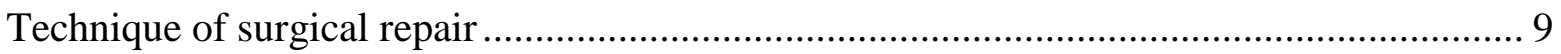

Comparison of Different Techniques .............................................................................. 15

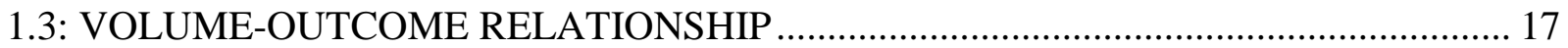

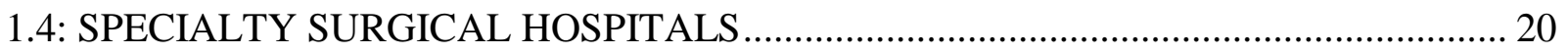

1.5: QUALITY OF CARE IN HERNIA SURGERY ………............................................ 23

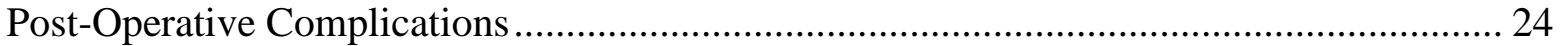

1.6: OVERVIEW OF ONTARIO HOSPITALS PERFORMING INGUINAL HERNIA

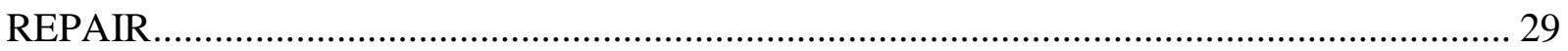

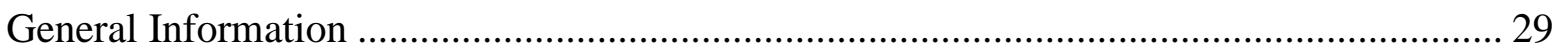

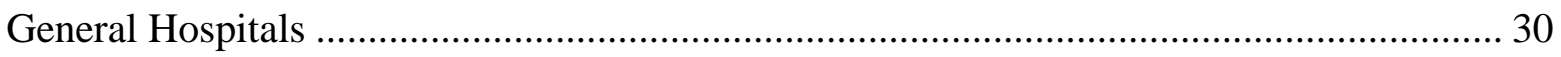

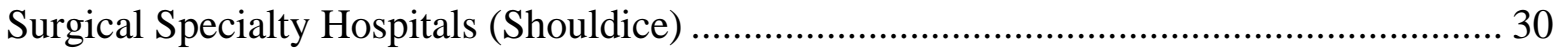

1.7: LIMITATIONS IN CURRENT KNOWLEDGE REGARDING THE QUALITY OF

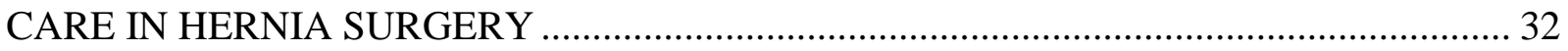

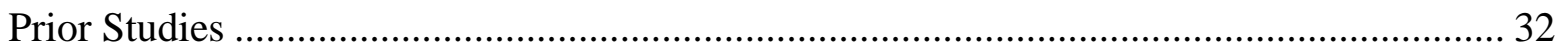

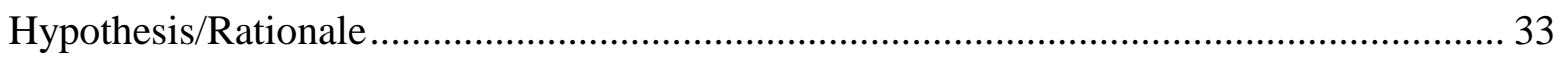

CHAPTER 2: METHODS ................................................................................................................ 35 


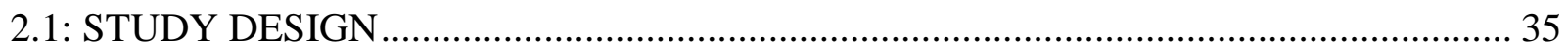

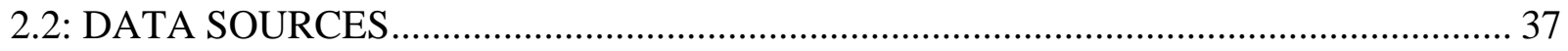

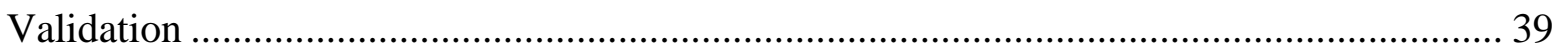

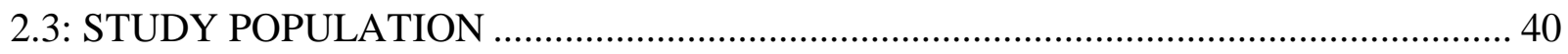

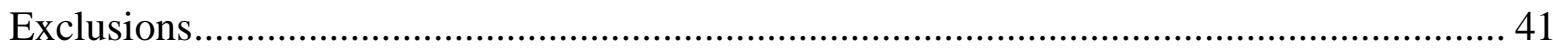

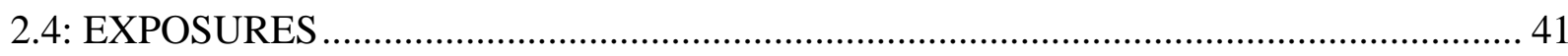

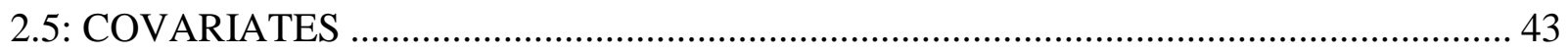

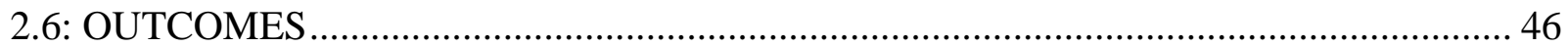

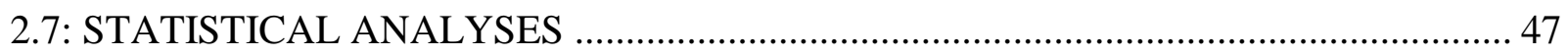

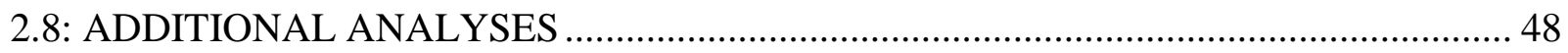

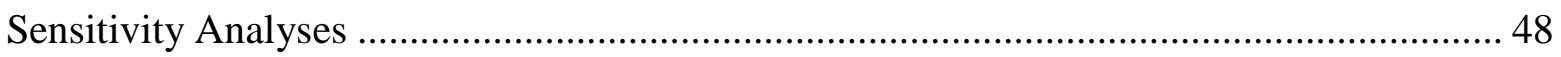

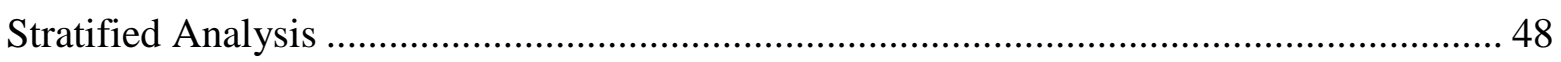

Shouldice Hospital Patient Selection............................................................................. 49

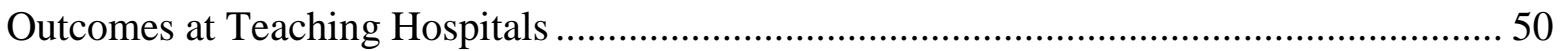

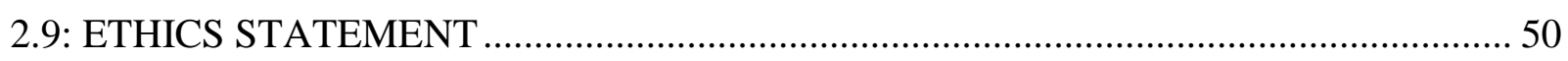

CHAPTER 3: RESULTS ................................................................................................................. 51

3.1: PATIENT AND HOSPITAL BASELINE DEMOGRAPHICS ...................................... 51

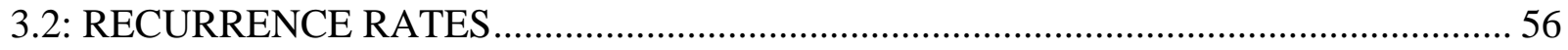

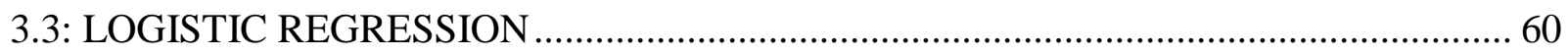

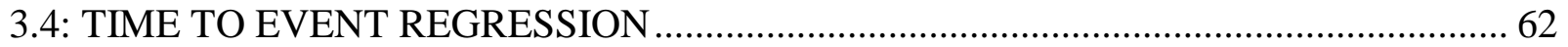

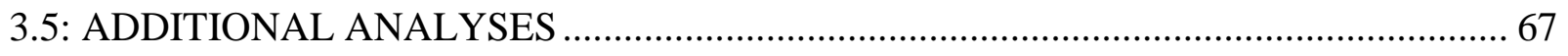

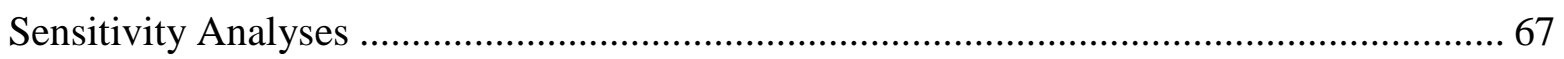

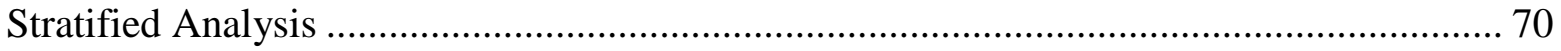

Shouldice Hospital Patient Selection................................................................................ 71

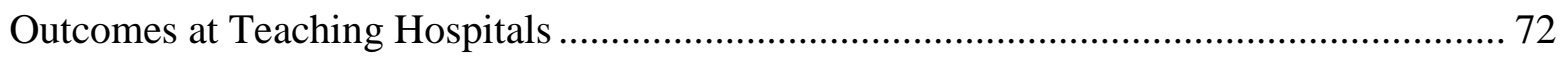

CHAPTER 4: DISCUSSION AND CONCLUSIONS .................................................................... 74

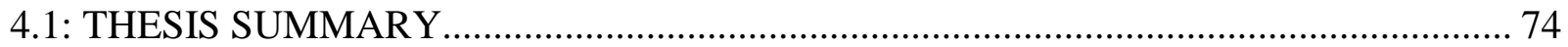

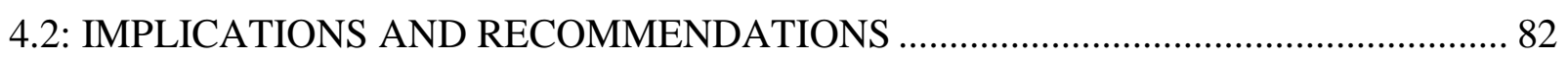

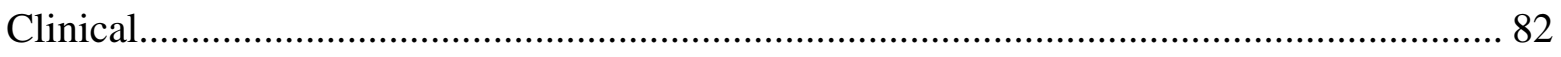

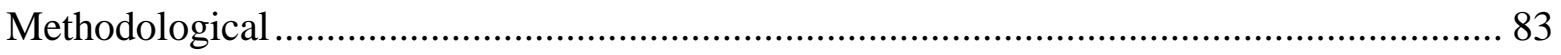




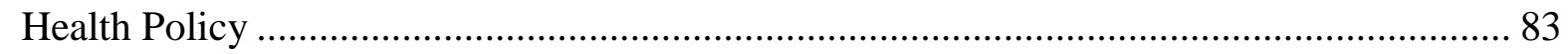

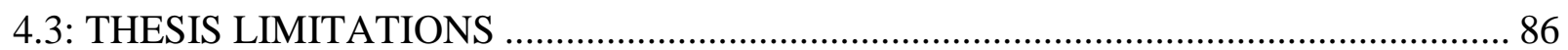

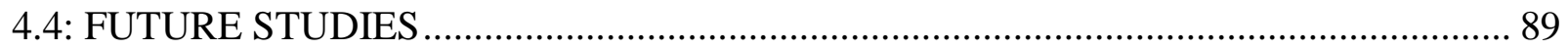

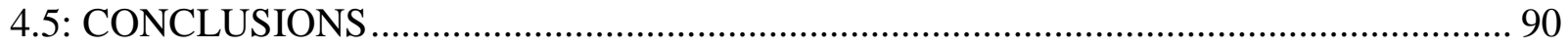

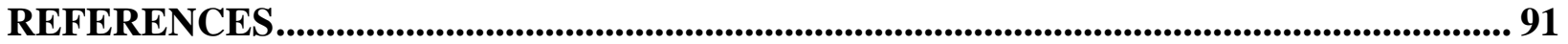




\section{LIST OF TABLES}

Table 1.1: Nyhus Classification of Groin Hernias * ........................................................... 4

Table 2.1: Variables definitions and sources. ................................................................. 38

Table 2.2: Collapsed adjusted clinical groups (CADGs) with examples of the conditions.......... 44

Table 3.1: General cohort characteristics based on hospital volume and type......................... 53

Table 3.2: Patient level variables by hospital volume and type.......................................... 54

Table 3.3: Recurrence Statistics according to hospital volume and type ............................... 56

Table 3.4: Patient level variables by hospital volume and type (Recurrences) ......................... 58

Table 3.5: Logistic regression results - Unadjusted and adjusted for patient-level variables ...... 61

Table 3.6: Risk of Hernia Recurrence by Hospital Volume and Type (Cox Regression -

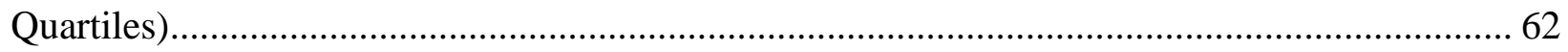

Table 3.7: General cohort characteristics based on hospital volume and type (Terciles)........... 64

Table 3.8: Risk of Hernia Recurrence by Hospital Volume and Type (Cox Regression - Terciles)

Table 3.9: Sensitivity Analysis -Cox Regression Limited to Healthy Patients......................... 68

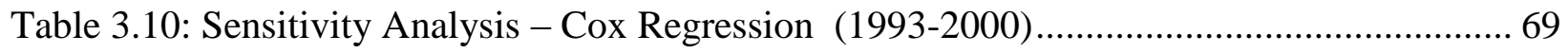

Table 3.11: Sensitivity Analysis - Cox Regression (2001-2007) ..........................................69

Table 3.12: Distribution of Primary Inguinal Hernia Repair Patients in Ontario Teaching

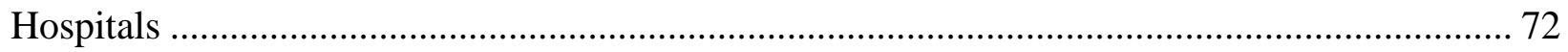

Table 3.13: Risk of Hernia Recurrence at Ontario Teaching Hospitals ................................. 73 


\section{LIST OF FIGURES}

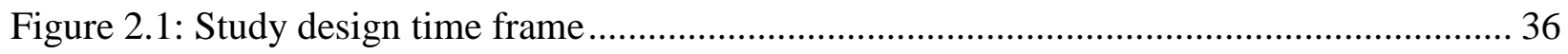

Figure 3.1: Hernia volume-outcome study exclusions .................................................. 51

Figure 3.2: Probability of Recurrence By Hospital Volume (Quartiles) .................................. 63

Figure 3.3: Probability of Recurrence By Hospital Volume (Terciles) ................................. 66

Figure 3.4: Risk of Recurrence (Stratified by Groups) ................................................. 71 


\section{CHAPTER 1: BACKGROUND}

\section{1: INGUINAL HERNIA EPIDEMIOLOGY}

Inguinal hernias (also known as groin hernias) occur as result of the protrusion of the contents of the abdominal cavity (bowels) through the inguinal canal into the groin. This leads to discomfort and pain for the patient, and can lead to complications, thus often requiring surgical intervention (1). Although the exact incidence and prevalence of inguinal hernia worldwide is unknown, it is very common and an estimated 20 million surgical procedures for inguinal hernia are performed each year all over the world (2). Operation rates specific to each country vary greatly, but range between 100-300 procedures per 100,000 persons per year (3).

Although inguinal hernia is a condition which can occur in both sexes, majority of the patients suffering due to this disorder are men (the male to female ratio is approximately 7:1). Individuals across all age groups can develop inguinal hernias, however the incidence increases with age. The lifetime risk of developing an inguinal hernia is approximately $27 \%$ for males, however this number is significantly lower for females, who have a lifetime risk of $3 \%$ (4). Prevalence overall in the population is estimated to be approximately 3-4\% (5).

Bilateral inguinal hernias may be observed in up to $20 \%$ of the affected adult population (6). According to Statistics Canada, hernia repair is the third most commonly performed surgical procedure in Canada; an excess of 50, 000 hernia surgeries are performed every year (5). In the 
United States an estimated 750,000 inguinal hernia surgeries are performed annually (7), thus making this disorder important from a population, health policy and economic perspective.

\section{2: MANAGEMENT/REPAIR OF INGUINAL HERNIAS}

\section{Anatomy/Origin of Groin Hernias}

The two broad classifications for inguinal hernias are direct and indirect; these designations are in reference to the location of the herniation in relation to the inferior epigastric arteries which are located on the abdominal wall as well as an anatomical region known as Hesselbach's triangle which is defined by the inferior epigastric artery, rectus muscle and inguinal ligament. It is generally believed that indirect hernias have a congenital component associated with them, whereas it is widely believed that direct inguinal hernias do not result due to a congenital defect (8).

Instead it is believed that direct inguinal hernias are acquired due to deficiencies in the tissue of the transverses abdominis muscle (this muscle constitutes the floor of the inguinal canal).

Therefore, direct hernias can herniate directly through the weak area in the muscle located in the inguinal canal floor; this is in contrast to indirect inguinal hernias, in which the protrusion of bowel contents can occur via the potential space of the processus vaginalis and through the path of the spermatic cord. Femoral hernias, which are another type of groin hernia and believed to develop as a result of increased intra-abdominal pressure (which may be a result of comorbid 
conditions). Women who have children may therefore have a predisposition to developing a femoral hernia as a result of a defect in the pelvic floor muscles (which can occur as a result of previous childbirth) (8).

\section{Classification of Groin Hernias}

Several classification systems to organize various types of groin hernias have been created, which can range from being simple classification systems to complex ones with up to 20 categories (9). Most classification systems take into account the defect's location (that is, whether it is a direct, indirect or femoral hernia), as well as the size and recurrent nature of a hernia (8).

Differentiating between various hernia types can be difficult to do prior to an operation, therefore an approach which is consistent from one case to another can help provide important information regarding inguinal hernia types that could then allow institutions and researchers to compare outcomes between repairs of different hernia types. Currently, there is no consensus amongst experts about which classification system is the best to adhere to, however the Nyhus classification system (Table 1.1) is well known and often cited by experts (10). 
Table 1.1: Nyhus Classification of Groin Hernias *

Type I (Indirect inguinal hernia)

- Internal inguinal ring normal

Type II (Indirect inguinal hernia)

- Dilated internal inguinal ring with the posterior inguinal wall intact

Type III (Posterior wall defects)

- Direct inguinal hernia

- Indirect inguinal hernia: Dilated internal ring with large medial encroachment on the transversalis fascia of Hesselbach's triangle

- Femoral hernia

Type IV (Recurrent hernia)

* Adapted from Nyhus LM, Klein MS, Rogers FB. Inguinal hernia. Curr Probl Surg 1991; 28:418.

Although the importance of classification systems cannot be denied, in a review paper titled "Classification of groin hernia: Milestones" by Lloyd Nyhus, the author writes:

"Interest in classifying groin hernias as to various identifiable types began in the late 1960s. Since then, innumerable attempts have been made to improve upon prior proposals so that the 
subject of hernia classification has become unnecessarily complicated. In addition, there has been a tendency to make decisions concerning the details of classification after the inguinal areas have been operatively opened. This, therefore, precludes the opportunity to utilize a superior operative approach, which might include one of the posterior preperitoneal repairs. The plea is for a preoperative evaluation that allows the surgeon to move forward with confidence that he or she has chosen the best operative approach technique to cure the patients groin hernia.

Now is the time for the classic "one-operation-fits all" philosophy to be rejected. Is it necessary to use prosthetic mesh for every hernia repair, regardless of hernia type? The answer is certainly negative. However, for the surgeon to understand the various prerogatives available in decision making, complete understanding of anatomical factors are necessary. In other words, the classification must clearly help us to understand the anatomic changes in a given hernia patient and thus lead our thought process toward the appropriate corrective measure. This is the position we always have espoused." (11).

This quote perfectly illustrates that while classification schemes are a useful tool for preoperative evaluation, that the focus should be placed on understanding and fulfilling individual patient needs, rather than classifying inguinal hernias into categories, as this is not always an easy, or time worthy task to undertake.

\section{Risk Factors}

There are several known factors, which can increase an individual's risk of developing an inguinal hernia. A non-exhaustive list is presented below:

- Male gender: As mentioned previously, males are far more susceptible to developing an inguinal hernia than females due to anatomical features. (12). 
- Family history: The risk of developing an inguinal hernia can increase if an individual has a first degree relative (parents/siblings) with the same condition (12).

- Obesity: Moderate or severe obesity can result in constant increased pressure on the abdomen, which can contribute to the development of a hernia (12).

- Pregnancy: This can cause weakening of the abdominal muscles and can also result in increased pressure inside the abdomen (12).

- Comorbidities: Having a condition such as cystic fibrosis, chronic obstructive pulmonary disorders (COPD), or other pulmonary disorders which cause excessive coughing and pressure in the abdomen, can result in an inguinal hernia due to repetitive straining (13).

- Chronic cough: A chronic cough due to a medical condition (usually chronic), or due to smoking, increases risk of developing an inguinal hernia due to repetitive straining and pressure in the abdominal cavity (13).

- Smoking: Studies of connective tissue which has been obtained from inguinal hernia patients have shown that smoking may cause hernia formation as a result of defective connective tissue metabolism. It has also been reported that smoking is a significant risk factor for recurrence of inguinal hernias, also likely due to abnormal connective tissue metabolism found in smokers $(14,15)$.

- Chronic constipation: This condition can lead to straining during bowel movements and this can lead to the formation of an inguinal hernia. Straining during urination can also result in a similar pressure in the abdominal area which can increase risk as well (12). 
- Vocational exertion: Individuals with jobs that require them to stand for long periods of time or engage in heavy physical labour can potentially be at an increased risk of developing an inguinal hernia (14).

- History of hernias: A personal history of developing an inguinal hernia may indicate that a patient is at an increased risk of developing an additional hernia on the opposite side (or alternatively, develop a recurrence on the same side) (16).

\section{Symptoms and Diagnosis}

The discovery of inguinal hernias in patients can be incidental during a physical examination, in which case the hernia is described as asymptomatic, or they may be presented by the patient as a bulge. Inguinal hernias can be associated with mild symptoms (pain), which can be worsened as a result of physical activity or straining which causes an increase in the pressure within the abdominal cavity. Several complications can result, including an irreducible incarceration of the bowels within the hernia sac, or strangulation of the bowels when the hernia sac is very constricted. This strangulation can cause a bowel obstruction which constitutes a medical emergency. Medical imaging is seldom used to make a diagnosis as clinical features and a physical examination are often enough to make a diagnosis. The best way to diagnose inguinal hernias is to ask the patient to stand and to strain against a held breath (this is known as the Valsalva maneuver $)(7,17,18)$. 
Diagnosis of patients who do have groin pain but lack clinical features such as a groin bulge is more difficult. Such patients may be suffering from a muscle strain rather than a hernia, however it is best to be cautious and further investigation is warranted if the patient reports a groin bulge, even if it is not found during physical examination. Femoral hernia patients may complain of pain in the upper thigh region rather than present with a groin bulge, depending on the type of herniation that has occurred. These types of hernias are especially difficult to diagnose in elderly or obese patients; in these cases, medical imaging may help make a diagnosis. Femoral hernias which are difficult to diagnose are often found in elderly female patients, however the most common inguinal hernias are indirect ones $(7,19)$.

\section{Treatment Options}

Most inguinal hernias can be reduced (that is, they can be pushed back into the abdominal cavity) and do not have much associated tenderness, in which case elective surgery to repair the disorder can be conducted within a few weeks. However, there can be more serious cases which involve incarceration of the contents of the abdominal cavity in the hernia sac (incarcerated hernia), or strangulated hernias, in which there is an obstruction within a segment of the bowels due to the presence of the inguinal hernia. In such cases, immediate repair is suggested, to prevent complications to the bowels or other visceral contents due to strangulation (as blood supply may get cut off, resulting in tissue necrosis) $(7,20)$. 
Early diagnosis can reduce rates of mortality and morbidity, however roughly 2,000 patients per year die worldwide every year as a result of clinical emergencies resulting from untreated complicated inguinal hernias. Bowel obstruction can cause nausea and vomiting, and this also warrants referral to a surgeon for emergency surgery (7).

Over many decades, various approaches to treat inguinal hernia have been developed by surgeons, which can be classified into various broad categories as defined in the following section.

\section{Technique of surgical repair}

Since there are multiple repair techniques available to treat inguinal hernias surgically, appropriate treatment can be individualized according to the patient's profile as well as surgical preferences. The following are the different surgical repair options available to surgeons to treat inguinal hernias.

\section{Group 1: Open Anterior Repairs}

Open anterior repairs, including the McVay, Bassini and Shouldice techniques, are referred to as such because they involve the surgeon opening the external oblique aponeurosis and then freeing the spermatic cord. After dissection of the transversalis fascia, a thorough inspection of the 
inguinal canal, the indirect space and the direct space is completed by the surgeon. The hernia sac is usually ligated during this type of surgery, and the defect in the canal floor is subsequently reconstructed $(8,21)$.

Open anterior repair techniques all use permanent sutures to repair the surrounding fascia and to repair the inguinal canal floor, although the different techniques vary in terms of their approach to the reconstruction of the defect. Use of these repair techniques by skilled surgeons, can provide satisfactory results for patients and all the techniques within this category have similar recurrence rates. In surgeries where the defect is very large, or with fascia that has poor quality, tension of the sutures that are put in place can lead to recurrence of the hernia. However, these techniques are still preferred by many surgeons and can be used with local anesthesia only (8, 22).

\section{Group 2: Open Posterior Repairs}

Iliopubic tract repair and the Nyhus technique are classified as open posterior repair techniques. This technique is different from the open anterior repair techniques described above because in this type of surgery, abdominal wall layers are divided superior to the internal ring and then the properitoneal space is entered. Dissection is then continued behind the inguinal region, and despite the different approach, this posterior dissection allows for excellent visualization of the concerning areas in an inguinal hernia repair. This repair type is also associated with positive results, however problems that relate to suture tension remain in this group as well. This repair 
technique is especially useful for hernias with multiple recurrences, as the posterior approach allows the surgeon to avoid scar tissue from the primary repair (is another technique was used).

This technique is mostly perfomed with the patient receiving general or local anesthesia, depending on the case $(8,23)$.

\section{Group 3: Tension-Free Repair (Mesh)}

Tension-free hernia repair techniques such as Lichtenstein and Rutkow techniques initially use the same approach as described above in the open anterior repair types. The difference is however, that instead of placing sutures the fascial layers together to fix the hernia defect (which can cause tension) the surgeon places a prosthetic, nonabsorbable mesh to fix the defect. This allows the hernia to be repaired without placing tension on the surrounding fascia because the mesh does not require excessive tension (24). This technique is very popular and benefits of this repair method have been widely cited (recurrence rates less than $1 \%$ have been reported) $(8,25)$.

In the repair type known as "mesh plug" or "plug and patch", the surgeon uses a mesh plug to repair the defect. Proponents of this technique state that it is easier to perform than the Lichtenstein repair, as it requires a smaller incision, fewer sutures to be placed, and less tissue dissection overall (25). 
Although this repair technique is often used by surgeons, some concern still exists regarding the safety of implanted prosthetic material in the long term. There can be a potential for infection or erosion or the material cannot be excluded completely but innovations in this area are constantly improving outcomes. Following this repair, several complications are often reported, including chronic groin sepsis and chronic pain. Despite these concerns however, the use of mesh for repairing inguinal hernias continues to be a popular. This type of repair can be completed with any type of anesthesia, but is usually completed as an outpatient procedure with local anesthesia $(8,26)$.

\section{Group 4: Laparoscopic Procedures}

Laparoscopic hernia repair gained popularity in the 1990s, along with open mesh repair, but this minimally invasive technique has also sparked significant controversy. When this technique was in the early stages of development, hernia repair was completed by placing a large piece of mesh on top of the peritoneum, over the entire inguinal region. This approach was eventually abandoned because it was associated with a likelihood of bowel obstruction and development of fistulae due to exposure of the mesh to the bowels $(8,27)$.

Most laparoscopic hernia repairs today are completed using either the total extraperitoneal (TEP) approach or the transabdominal preperitoneal (TAPP) approach. The latter approach involves the placement of laparoscopic trocars in the abdominal cavity; this allows the surgeon to approach 
the inguinal region from the inside. The mesh is then placed and covered with peritoneal tissue. Although this approach is a simple laparoscopic procedure, entrance into the peritoneal cavity is required for dissection. This can potentially be problematic because the bowels or vascular structures may be injured as a result of this approach $(8,28,29)$.

In contrast, in the TEP repair technique, the surgeon uses an inflatable balloon which is placed in the extraperitoneal space of the inguinal region. The balloon is then inflated which provides visualization and working space for the surgeon. In both the above mentioned techniques, the hernia sac is reduced, and a large piece of mesh is used to cover the entire inguinal region. Metal staples can be used to hold the mesh in place, however some surgeons believe this is an unnecessary step because it increases costs and also risks due to the possibility of nerve entrapment $(31,32)$. As an alternative to stapling or suturing, the use of fibrin glue can also be explored as a potential option $(8,33)$.

The advantage of these laparoscopic techniques is that the small incisions made for entry of the minimally invasive surgical equipment cause less pain and disability, thereby promoting faster recovery and as a result, better quality of life for the patient. Patients who do heavy manual labor can return to work sooner after their surgery due to less healing time required. Another advantage of these techniques is that bilateral hernias may be repaired simultaneously due to ease of access $(8,34)$. 
Finally, adopting a minimally invasive approach is particularly effective in patients who are suffering from a hernia recurrence after primary repair during which traditional repair techniques were used (35). In these individuals, repeating an open anterior repairs is associated with a higher failure rate as well as an increased probability of developing complications. Similar to the open posterior approach, the minimally invasive laparoscopic approach allows the surgeon to repair the hernia via a previously untouched space, thus avoiding prior scar tissue. The major disadvantages associated with laparoscopic surgery are factors such as the cost of the laparoscopic equipment, as well as the need for general anesthesia $(8,36)$.

\section{$\underline{\text { Shouldice Repair }}$}

Of special interest for the purposes of this study is the Shouldice repair (a type of mesh-free repair), which was developed by a world-famous Canadian surgeon who was the founder of the Shouldice Hospital in Ontario, Canada, a specialty hernia exclusive hospital. From its inception in 1945, hundreds of thousands of hernias have been repaired at Shouldice Hospital (37). This technique has evolved over the years and is both therapeutic and prophylactic.

The Shouldice repair is a pure tissue repair type and is referred to as a patient centered technique by the founders, because they state that it is a total concept that involves patient cooperation in preoperative preparation and also during early postoperative ambulation. The operative technique itself does have several features in common with other open groin repairs, but there are important differences in both the dissection and repair. In the Shouldice technique, the entire groin region is dissected out and this technique includes exploration for secondary hernias and 
weakness in the tissue. The laminated closure allows the defect to be repaired without tension, under local anesthesia. It is widely believed that this is a reliable repair method and is associated with low recurrence rates $(38)$.

\section{Comparison of Different Techniques}

The majority of inguinal hernias can be repaired safely and in a cost-effective manner by using an open anterior technique along with local anesthesia. A less than $4 \%$ recurrence rate has been reported for those hernia repairs which are performed without prosthetic mesh (39). However, in patients with direct hernias, or other complications (longstanding hernia or attenuated fascia, elderly patients), hernia repair using prosthetic mesh would likely be a better option. In a study which evaluated return to work it was reported that more $90 \%$ of individuals with jobs that required light activity were able to return to work within 10 days after undergoing tension-free mesh hernia repair (25). $3 \%$ or lower recurrence rates have been reported for these cases (40).

Recurrent hernias repaired with other techniques that do not use mesh have a reported recurrence rate of approximately $23 \%$ at three years according to some reports (41). Due to this statistic, it has been recommended that recurrent hernias are best managed with open anterior, posterior mesh repair or alternatively, with a minimally invasive laparoscopic procedure. Bilateral hernias can also be treated at the same time, using either a laparoscopic procedure or an open repair technique; the approach in each case however depends on the surgeon's preferred method and area of expertise. 
Laparoscopic herniorraphy is a minimally invasive procedure and therefore is becoming more common; newer technologies and innovations have revolutionized the methods used for this type of repair and several studies have indicated that this repair type is safe and allows for faster patient recovery and minimizes pain and discomfort following surgery. The recurrence rate following this technique has been reported to be less than $4 \%(42,43)$. An advantage of the laparoscopic technique for an initial repair appears to be related to faster recovery and an earlier return to pre-surgery activities/vocation (43). An important disadvantage to this repair type is that compared to other hernia repair techniques, laparoscopic surgery is significantly more expensive; some studies have indicated that the laparoscopic approach can be up to $40 \%$ more costly than other techniques. Intra-abdominal injury can also potentially occur during laparoscopic repair (44).

Laparoscopic hernia repair may be the most appropriate technique for treatment of recurrent or bilateral hernias. However, some individuals may prefer the minimally invasive technique due to a variety of reasons, and therefore, this repair type may be used during the initial hernia repair for certain patients. Untreated hernias can no doubt lead to serious complications if not repaired, however the true impact and nature of all complications that can result is not fully known. Decreased surgical intervention may lead to increased number of incarcerated or strangulated hernias resulting in hospitalization (45). 
A Cochrane review was conducted by Amato et al. in 2009 which was aimed at evaluating the safety of the Shouldice repair technique in comparison to other non-laparascopic hernia repair techniques. 16 trials contributed to the completion of review and 2566 hernias were analyzed in the Shouldice group (1121 mesh and 1608 non-mesh). The results indicated that the Shouldice repair technique is the best amongst the non-mesh technique in terms of inguinal hernia recurrence, and that while the use of mesh can be associated with lower recurrence rates, it can also be associated with increased patient discomfort during recovery (46).

Another Cochrane review conducted by McCormack et al. (47) revealed that when mesh is used along with laparoscopic hernia repair, it is associated with a $30-50 \%$ relative reduction in the risk of hernia recurrence. However, when recurrence rates after laparoscopic and open mesh techniques were compared, no significant difference was found. This study did reveal in addition, that laparoscopic hernia repair resulted in less persistent pain and complaints of numbness from patients. It was reported that patients were able to recover faster if they had a minimally invasive surgery but also that the operation time was longer and that there is a higher risk of serious complications, because intra-abdominal injuries (such as visceral or vascular injuries) occurred at a higher rate with this type of repair.

\section{3: VOLUME-OUTCOME RELATIONSHIP}

Volume-outcome relationships have been studied considerably in the past, due to the potential high impact implications of such relationships in various areas of medicine. Numerous studies on this topic have indicated that there is an inverse relationship between hospital volume (that is, the 
number of cases treated) and outcomes (patient complications), for many different surgical procedures. One of the most notable studies in this area is a study by Birkmeyer et al. titled "Hospital Volume and Surgical Mortality" published in the New England Journal of Medicine in 2002 (48). This study used a nationwide sample in order to evaluate the mortality rates following cardiovascular and cancer resections after treatment at facilities of different volumes. The study revealed that those institutions which performed a high volume of a certain procedure had better outcomes (reduced mortality rates) as compared to those institutions which performed a lower volume of procedures. Other similar studies have revealed that the outcomes of procedures such as primary angioplasty also are improved when initial treatment is completed at a high volume facility instead of a low volume center (49).

However, although many studies have shown the existence of a relationship between volume and outcomes, the causes for such an effect are not always clear. It is not known if this relationship exists due to surgical experience as a result of repeating the same procedures at a higher rate (and therefore higher skill) than their counterparts at low volume facilities, or if this effect exists because those facilities which are able to treat a large volume of patients in the first place are those which have more advanced technology, a broader range of specialists and more resources in terms of staff overall (50).

As a follow-up to the 2002 study, Birkmeyer et al. released a new report titled, "Surgeon Volume and Operative Mortality in the United States" (51). This study was aimed at exploring what the relative importance of surgical experience was in relation to mortality outcomes. Results 
revealed that surgeon volume was in fact an important factor because it accounted for a large fraction of the volume-outcome trends observed. It was also revealed that surgeon volume had a different effect on outcomes based on the difficulty of the specific procedure. For instance, procedures such as aortic-valve replacement require a high degree of surgical skill and training, and for procedures such as this, a strong association between surgeon volume and improved outcomes was reported (49).

An important limitation of many volume-outcome studies is that administrative health data is used to study these relationships rather than clinical data, due to the statistical analysis required. This means then that the study is limited according to whichever type of dataset is used; for instance the study by Birkmeyer et al. described above used the Medicare dataset and is thus limited to those patients who are $65+$ years old. In our study for instance, our dataset is limited to those patients who had valid Ontario Health Insurance Plan (OHIP) health cards, whereas there may have been more individuals who sought treatment privately. Furthermore, there have been some studies which have indicated that studies which use administrative datasets are more likely to report statistical significance between outcomes of interest and volume than those studies which rely on clinical data, however this may not necessarily indicate that studies which use administrative records are poorer indicators of outcomes, as it may also be the opposite (52).

The same trends observed for improved outcomes in relation to surgeon volume can also be applied to improved outcomes with institutional volume (the study described in this thesis is an example of such a study) (53). Although volume outcome studies do have certain limitations, the 
overwhelming body of literature on this topic that continues to grow indicates that patients can experience improved outcomes by selecting high volume surgeons or high volume institutions. The data has demonstrated that highly specialized, high volume hospitals (such as the Shouldice hospital) have consistently reported better outcomes. Although it is not known what proportion of the effect observed is a result of the volume-outcome relationship, it can be said with confidence that the effect of volume on outcomes is often undeniable. Volume-outcome trends at general hospitals in Ontario had not yet been compared with a specialty hospital for hernia repair, hence this was the focus of our research (53).

\section{4: SPECIALTY SURGICAL HOSPITALS}

Those facilities which treat patients with specific medical conditions only are referred to as specialty hospitals. For example, there are hospitals which specialize in the care of psychiatric patients, rehabilitation, cancer care, women's health, pediatric care, as well as care for other specific chronic conditions and these can all be referred to as specialty hospitals (54). Cardiac, orthopedic or general surgical hospitals can also be considered specialty facilties.

As a result of a rapidly aging population and increased demand for healthcare, along with a limitation in resources, an ideal situation would be one where the quality of hospital care will increase but where costs will decrease simultaneously. Specialty hospitals which are aimed at treating specific diseases or conditions have often been proposed and tested as a model of healthcare delivery which can improve the quality of hospital care but also reduce costs (55). 
Specialty hospitals exist in many jurisdictions, however they can vary substantially in terms of specialties (that is, which diseases they treat), as well as in terms of whether they are government-run or privately owned. Proponents of specialty hospitals state that these facilities provide high quality services and that they allow for innovative treatments, and that focusing on specific conditions allows for higher volumes which are associated with better outcomes. It is understandable that those institutions which organize themselves around a narrow group of procedures can become experts in the procedure they complete or the diseases they treat, and this is due to the concentrated focus on specific conditions. The high volume of procedures completed can help to improve the quality of treatment received, and can also potentially result in reduction of overall costs (55).

Furthermore, it is believed that specialty hospitals are beneficial from the patient's perspective as they produce clinical efficiencies. This means that physicians are able to directly control the scheduling and triaging of patients, as well as other factors such as equipment use and purchase. By having a specialty hospital, the inefficiency associated with scheduling and use of facilities which were not designed appropriately for the condition being treated can be avoided. Furthermore, for those specialty hospitals which are surgical centers, the procedures completed are elective, and therefore, the scheduling of surgeries is not impacted greatly by emergency procedures (56). 
Although speciality hospitals are associated with many benefits as mentioned above, there are many experts who oppose the use of specialty hospitals. This is because these experts argue that as a result of performing surgeries/procedures on an elective basis, that specialty hospitals are able to "cherry pick" patients who otherwise would help to subsidize general hospitals, and that these specialty centers often leave the more complicated or burdensome cases for the general hospitals to deal with. The main point of contention is that specialty hospitals leave large general hospitals to bear the financial brunt of necessary but relatively unprofitable services (such as ERs and burn units) (57).

Evaluation of the efficiency of specialty hospitals becomes difficult due to the vast diversity of hospital types; therefore conclusions on the performance of such hospitals are mixed based on the set up of the institution being studied (58). Most specialty hospitals in the world are within the US, are owned by physicians, and focus on a specific set of procedures. Specialized hospitals also exist in the UK, India, Finland and in many countries all over the world. Areas of specialization can include cardiology, orthopedic surgery, women's health, plastic surgery, brain and spine, eye hospitals, and many more (59).

Lastly, patient satisfaction, which is a very important measure of quality in patient care, is reported to be higher in specialty hospitals. In summary, making generalizations regarding the impact of specialty hospitals is difficult due to the wide range of conditions treated by different institutions and various set-up types. In order to effectively understand the diversity amongst 
specialty hospitals, further studies are required to specifically evaluate individual institutions or treatment centres (60).

\section{5: QUALITY OF CARE IN HERNIA SURGERY}

The quality of care provided to inguinal hernia patients can differ in many ways. In most general hospitals, inguinal hernia repair is treated as a day surgery procedure, but Shouldice hospital treats patients on an inpatient basis; therefore length of hospital stay differs greatly between groups. The complications that can result after primary repair are mostly minor and self-limited in nature. Superficial wound infections and hematomas are amongst the most commonly reported problems and they are treatable complications.

More serious complications, such as hemorrhage, osteitis and testicular atrophy can occur in less than $1 \%$ of patients who undergo primary inguinal hernia repair (61). Our study chose to focus on hernia recurrence as the outcome of interest because this is the most common post-operative complication and remains an issue which can drain healthcare resources and cause unnecessary suffering for patients. Hernia recurrence and other complications that can be experienced by patients post-operatively are described below. 


\section{Post-Operative Complications}

\section{Hernia Recurrence:}

Recurrence is the most common long-term complication that can result after inguinal hernia repair. Approximately 50\% of hernia recurrences do not occur until 5 years have passed since the primary repair and a further $20 \%$ of recurrences may not occur for $15-25$ years (62).

The recurrence rates that are reported in the literature for surgically treated hernias can vary drastically, depending on the length of the follow-up period as well as other factors such as the time of technique used during initial repair. In most reports, recurrence rates can vary between $5 \%$ and $8 \%$ for indirect hernias and these figures are slightly higher for direct hernias. In some studies, depending on the population studied, recurrence rates after repair of a recurrent hernia can be up to $30 \%$ (62). Hernia recurrence does not always occur because this is usually a result of the breakdown of a repair that was performed fascial suturing. A breakdown of the tissue may occur because of incomplete dissection, weak quality of the tissue (which can be due to longstanding large hernias) or because the patient did not allow enough time to rest before returning to normal daily activities. Comorbidities such as obesity (which increases the pressure on the abdominal area), steroid use and chronic obstructive pulmonary disease (associated with respiratory symptoms which can cause straining in the abdominal cavity), can all influence wound healing and can therefore affect the recurrence rate (63). 


\section{Nerve Entrapment:}

Nerve entrapment is a serious complication of inguinal hernia repair. However, most nerve entrapment syndromes respond well to nonsteroidal analgesics and resolve with time as they are generally self-limited in nature. However, in some cases chronic neuralgia can develop, which is more serious (66). Entrapment of the ilioinguinal nerve as a result of the surgical repair can cause pain in the groin; if a patient is asked to extend their hip, this can greatly exacerbate the pain. If the genital branch of the genitofemoral nerve is injured during surgery, this can result in hypersensitivity of the groin as well as the upper thigh. Diagnosis for this problem can involve the injection of a local anesthetic drugs along these nerves (64).

After a period of non-operative care, and if symptoms are severe and impact quality of life considerably, some patients with nerve entrapment are referred for surgery and possibly even excision of the nerve which was entrapped. However, the success rate of this type of surgery is not extremely high, because it provides relief in less than $60 \%$ of patients. Although laparoscopic hernia repair by virtue of being minimally invasive offers greater protection to the ilioinguinal and iliohypogastric nerves due to where they are located, there have been reports of injuries to the femoral nerves even with the minimally invasive technique (64). 


\section{Wound Infection:}

There is a low risk of infectious complications following inguinal hernia repair, however should an infection occur, this is a significant risk factor for recurrence of the hernia because proper healing is impaired. The risk of infection can be increased due to many clinical or technical reasons following hernia repair, and this includes factors such as the use of mesh, location of insertion of the mesh into the abdominal cavity, which technique was used by the surgeon during primary repair, the use of drains as well as if the operation was an emergency procedure (65).

Wound infections at the site of the surgery are associated with a greater than $80 \%$ risk of hernia recurrence, and are thus a risk factor for hernia recurrence. There are also several clinical risk factors which are associated with a wound infection in a hernia repair, and these include: obesity (increased pressure on the abdominal cavity), diabetes, immunosuppression (because the host defenses of the body are weaker and are unable to control infection), heart failure, and chronic obstructive pulmonary disease and/or smoking (65).

\section{Chronic Pain:}

Chronic pain is a frequent and serious consequence of various surgeries, including inguinal hernia repair. Although the precise incidence of chronic pain following inguinal hernia repair is not known, several epidemiological studies have suggested that post-operatively about $20 \%$ of 
patients are affected due to chronic pain symptoms and that in roughly $12 \%$ the intensity of the pain is so severe that it impairs activities of daily living. After the surgery, if pain persists for more than 3 months, this is classified as chronic pain (66).

The underlying pathogenesis for the development of chronic pain is poorly understood. Although a nerve lesion may be a prerequisite to the development of this complication, there are patients who report postoperative sensory abnormalities but do not complain of pain, thus a nerve lesion may not be the only factor in these situations. An inflammatory response by the body in response to mesh repair may also cause chronic pain. However it is often difficult to distinguish between the various causes of chronic pain after primary repair as several factors can be contributing to this complication (66).

The degree of pain reported by patients can be mild to severe; the pain may last from 2 to 6 days immediately after operation and then subsides. Recovery time for some patients is a few days and for others it can be longer. Patients may confuse chronic pain after surgery with a recurrence of the hernia $(62,67)$.

This is not always true because pain after the repair does not necessarily indicate a recurrence, as there are cases where the pain can persist for longer, depending on the state of the patient. Long lasting and chronic pain that results after inguinal hernia repair can be a result of nerve entrapment and this warrants further investigation. A pain management specialist can help diagnose this disorder and in very severe cases, as mentioned previously, surgical repair may be indicated if the quality of life reported by the patient is extremely poor. As a result of this 
treatment which involves exploration and removal or remaining sensory nerve, the patient will continue to report numbness in the affected area, however the pain would not be as severe or as disabling as before (67).

\section{Bleeding:}

If injury to the inferior epigastric vessels occurs during dissection or during the stapling of mesh, this can result in major bleeding during the surgery. This is a rare complication however and is controlled with sutures or clips because electrocautery is usually not effective with this sort of an injury (68).

\section{Testicular damage:}

During dissection of the spermatic cord in inguinal hernia repair, although it is rare, the spermatic vessels may suffer injury. This is reported especially in the technique which uses split mesh for repair of the defect. Should this complication occur, the spermatic cord must then be dissected and repaired subsequently. This is why during repair, it is recommended that the spermatic cord be handled with much care, as excessive traction can result in injury. It must be noted also that this occurs more frequently when a recurrent hernia repair is being performed and is not a common complication overall (69). 


\section{$\underline{\text { Seroma: }}$}

In those hernia repair techniques which involve the use of mesh, a seroma can occur postoperatively. This is a tumour-like accumulation of fluid that occurs within the tissue as a result of an immune/inflammatory response to the mesh that is inserted during surgery (the body recognizes it as foreign material). The use of a mesh which has larger pore size can reduce the chances of developing this complication (70).

\section{Hematoma:}

A hematoma can manifest as a result of collection of clotted blood after incisional hernia repair, and also occurs in $1-5 \%$ of patients who undergo laparoscopic hernia repair. This complication case result because of unintentional injury to the superficial blood vessels preset in the abdominal wall. Electrocautery is the best method to avoid this complication, as it can be completed during the surgery and greatly reduces the risk of development of a hematoma postoperatively. Aspiration is required in those cases where a large hematoma does form postoperatively (70).

\section{6: OVERVIEW OF ONTARIO HOSPITALS PERFORMING INGUINAL HERNIA REPAIR}

\section{General Information}

Ontario has four different hospital types including public, private, federal as well as cancer care Ontario Hospitals; not all hospital sites have surgical facilities. Furthermore, there are seven 
private hospitals currently providing services under the Private Hospitals Act. Six of these hospitals receive compensation and funding from the Ministry of Health, Ontario (71).

\section{General Hospitals}

Surgeons at general hospitals across Ontario use a variety of hernia repair techniques, depending on previous training and availability of resources. Procedural volume also varies greatly between hospitals; institutions which lack appropriate staff, funding or resources, perform fewer inguinal hernia repairs, whereas larger centers or teaching hospitals may perform a higher volume of inguinal hernia surgeries.

\section{Surgical Specialty Hospitals (Shouldice)}

Shouldice Hospital is an inpatient facility with five operating rooms located in Thornhill, Ontario, Canada. There are 11 full-time surgeons who perform more than 7500 hernia repairs every year. Due to its popularity, the Shouldice hospital has attracted patients from outside Canada as well, and they report that $50.9 \%$ of their patients come from outside the metropolitan Toronto area and $20.6 \%$ are international patients (72). 
In their promotional materials, the Shouldice Hospital reports low hernia recurrence rates, at a lower price than what is charged by many US hospitals. However it has been noted that they do not accept complicated cases. According to the Shouldice Hospital their high success rate is due to: surgeon excellence, high patient volumes, the Shouldice diet to reduce abdominal fat and reduce complications after the surgery, a 3 day stay following the procedure instead of treating it as an outpatient procedure like general hospitals do, and lastly, the previously mentioned Shouldice technique (which allows more time for exploration of the abdominal cavity to find "hidden hernias"), thus reducing chances of recurrence $(73,74)$.

The Shouldice hospital reports that $94.3 \%$ of the operative procedures since 1945 at Shouldice hospital have been groin hernia repairs, made up of 55.3\% indirect inguinal, $35.7 \%$ direct inguinal, and 3.3\% femoral; thus, Shoudlice hospital is a specialty hospital that is devoted almost exclusively to the treatment of inguinal hernias. Other hernia repair types are also repaired however, including: incisional, umbilical, epigastric, interstitial, Spigelian, and flank hernias, which comprise the remaining 5.7\%. The Shouldice hospital further reports that a significant $15.4 \%$ of all inguinal hernias are indeed secondary hernias which are found at the time of surgery (as reported in a review conducted by Shouldice Hospital) (74).

Shouldice hospital surgeons believe that such secondary hernias and weaknesses, if missed, may well account for the widely held figure of at least $10 \%$ recurrence rate following inguinal hernia repair. By searching for secondary hernias during primary repair, Shouldice hospital states that they are able to provide better patient care. Most patients at Shouldice are middle aged, with 
roughly a quarter being older than 65 . This in turn influences the type of hernias seen, as sliding hernias, for example, are more frequent in the older age group. As well, only $6.3 \%$ of patients are female; therefore, the incidence of female to male inguinal hernias is much lower than generally quoted $(74,75)$.

Recurrent groin hernias are also repaired at Shouldice and formed a significant portion of the patient population: a full $10.4 \%$ of hernias repaired in the last 11 years. The Shouldice hospital reports that this unusually high percentage of recurrent hernias, out of keeping with what is generally seen in most surgical units, is likely due to the hospital's reputation of specialization in hernia repair resulting in more problem cases being attracted (74).

\section{7: LIMITATIONS IN CURRENT KNOWLEDGE REGARDING THE QUALITY OF CARE IN HERNIA SURGERY}

\section{Prior Studies}

It has previously been reported that Shouldice Hospital has a $1 \%$ recurrence rate for inguinal hernia repairs by various groups. A 21-year follow-up study conducted by Glassow in 1976 reported that between 1945 to 1973 , roughly 85,000 patients underwent surgery at Shouldice hospital, and that the reported inguinal hernia recurrence rate was $0.6 \%$ (76). 
The aim of another follow-up study carried out at Shouldice Hospital in 1986 (77), was to assess the reliability of the Shouldice repair by evaluating the effect of various suture materials, surgeon expertise patient age and duration of post-operative stay on recurrence rates.

This study revealed that over a 12 year period, 696 patients underwent 718 surgeries under general anaesthesia for primary inguinal hernia. Of these patients, 22 either simultaneously or subsequently, had bilateral inguinal hernias; however bilateral operation was not undertaken at one time for any of these patients. The minimum interval that was reported between operations was 21 days. 55 percent of the surgeries were right-sided and 65 percent were indirect (77). Various factors such as the duration of stay, overnight stay or a longer stay at the facility did not influence the recurrence rate. The mean duration of stay was 4.3 days.

These result of this study confirmed the clinical reliability of the Shouldice operation for inguinal hernia, a fact that was already well-recorded in the surgical literature; a recurrence of $1 \%$ was reported (77).

\section{Hypothesis/Rationale}

The studies mentioned in detail above were conducted many years ago, and although they provide valuable information regarding historical recurrence rates at Shouldice Hospital, more recent studies to evaluate recurrence rates after treatment at Shouldice Hospital have not been completed. The availability of administrative data from the Ontario Health Insurance Plan (OHIP) physician billing database, as well as several other administrative databases allows us to 
evaluate these recurrence rates via a thorough process, by observing time to recurrence and overall recurrence rates in different hospital categories.

Furthermore, even though recurrence rates at Shouldice Hospital have been evaluated numerous times and have usually been reported as being low, the comparison of surgical specialty hospitals vs. general hospitals in Ontario to evaluate inguinal hernia outcomes has not been completed. If outcomes of hernia surgery are better at a specialty hospital, this may indicate a benefit for patients and may indicate that Centers of Excellence, such as Shouldice Hospital, are more effective at treating specific patient types.

The central theme of this thesis is to compare inguinal hernia surgery outcomes at general hospitals in Ontario (both low volume and high volume), but especially to compare outcomes at high volume general hospitals with outcomes at a high volume specialty hospital (Shouldice Hospital), to observe if there is any added benefit to treatment at a specialty hospital over treatment at a high volume general hospital. The study will also reveal if the $1 \%$ recurrence rate reported by Shouldice Hospital is accurate in the modern era, and how this older technique compares to those techniques used at general hospitals (where mesh and laparaoscopic repair techniques became commonplace in the 1990s). The availability of advanced statistical software will allow us to conduct research which was not possible at the time of the prior studies which evaluated recurrence rates at Shouldice Hospital. 


\section{CHAPTER 2: METHODS}

\section{1: STUDY DESIGN}

We conducted a retrospective cohort study using population-based administrative health data for the province of Ontario. Randomized clinical trials, which are considered one of the most reliable study design methods, are often not an option when conducting research to assess surgical outcomes, due to ethical and practical reasons. Such a study would be expensive to conduct, would require a long follow-up, and it would also be difficult to conduct as standardization of procedures would be difficult to coordinate. Therefore, a retrospective cohort study, which allows for the posthoc evaluation of outcomes, allows for the reliable observational assessment of the specified cohort (78).

For the purposes of this study, the cohort of patients, their exposure statuses, as well as their outcomes after the exposures, were all identified after follow-up had been completed. This study design is beneficial as it allows for time-efficiency when the analyses are being completed, as the data has already been gathered in the past; however, a disadvantage is that the data collected is often for other purposes, for instance, in this case, for physician billing purposes, rather than for the study. 
For the study outlined in this document, a cohort of persons who underwent primary elective hernia repair in the province of Ontario between January 1, 1993 and March 31, 2011 was identified via electronic administrative health data records.

This cohort of patients was followed to observe outcomes of interest (hernia recurrence) during the study period following their initial procedure. The primary objective of the study was to compare inguinal hernia recurrence rates between low vs. high volume general hospitals in Ontario and a high volume surgical specialty centre, the Shouldice Hospital. General hospitals in Ontario performing inguinal hernia repairs were divided into quartiles based on patient volume, with each quartile having approximately the same number of patients. Patients who underwent treatment at the Shouldice Hospital and these persons were categorized separately as they had treatment at a specialty hospital. (See Figure 2.1).

Figure 2.1: Study design time frame

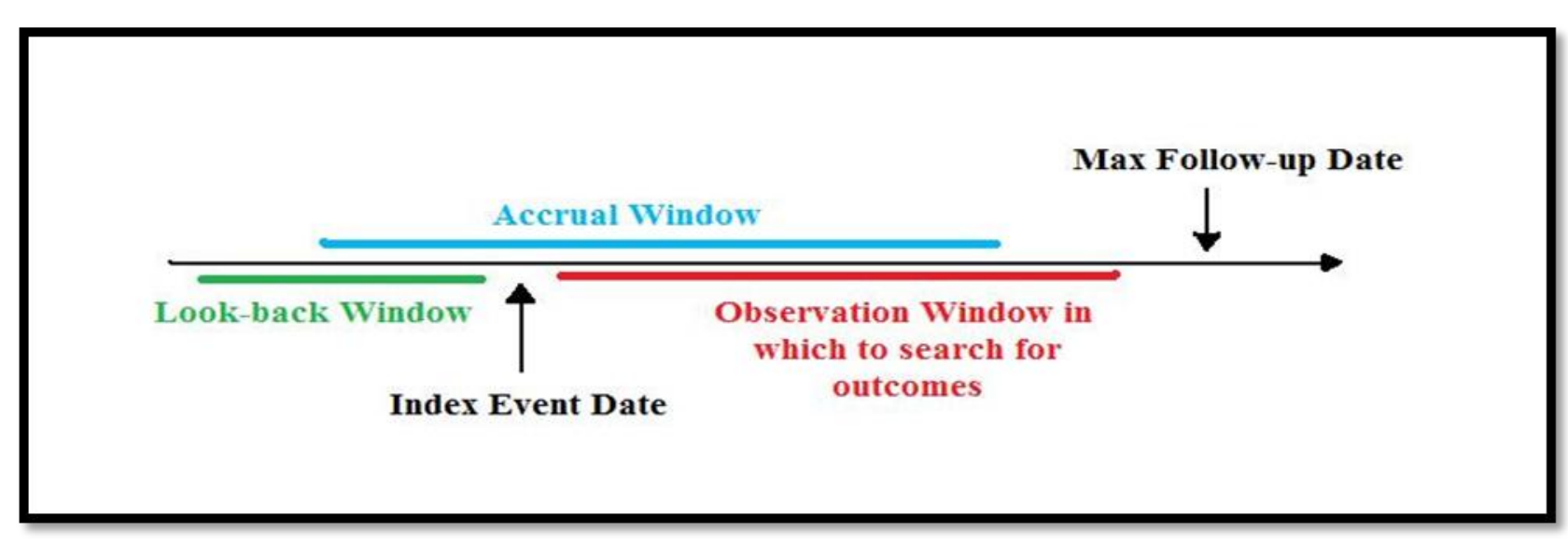




\section{2: DATA SOURCES}

Patients undergoing primary inguinal hernia repair in the province of Ontario during the study period were identified via linkage of records from Ontario health databases, including the Canadian Institute for Health Information (CIHI) database and the Ontario Health Insurance Plan (OHIP) physician billing database. The CIHI-DAD is a population-based database that contains information on all inpatient hospital admissions in Ontario. In addition to identifying inguinal hernia patients, the CIHI-DAD in conjunction with the provincial Registered Person's Database (RPDB), provides demographic details for each inguinal hernia patient including age, sex, comorbidity, region of residence (rural/urban and LHINs) and neighbourhood income level (79).

The OHIP billing database contains claims-based information from physicians across the province of Ontario who treat patients with OHIP coverage. A list of all variables used in the thesis is provided below (Table 2.1). Although the data sources used for this study are reliable and provide valuable provincial data, it is important to note some limitations of the datasets: the OHIP billing database does not include claims information from physicians who do not submit fee-for-service claims. Furthermore, the data sources do not contain information for any events that occurred in federal jurisdiction prisons or first nations reserves, and also do not account for international patients, who do constitute a significant proportion of Shouldice hospital patients. 


\begin{tabular}{|c|c|c|}
\hline Variable & Definition & Source \\
\hline Age & $\begin{array}{l}\text { Patient age at time of initial } \\
\text { hernia surgery (index event) in } \\
\text { years }\end{array}$ & RPDB \\
\hline Sex & Patient gender & RPDB \\
\hline Year of Index Event & $\begin{array}{l}\text { Year of first inguinal hernia } \\
\text { surgery }\end{array}$ & OHIP and CIHI \\
\hline ADG Comorbidity Score & $\begin{array}{l}\text { Johns Hopkins' Aggregated } \\
\text { Diagnosis Groups (ADGs) } \\
\text { categorical information to } \\
\text { assess patient comorbidity }\end{array}$ & CIHI \\
\hline LHIN & $\begin{array}{l}\text { Local Health Integration } \\
\text { Network in which patient's } \\
\text { residence is located }\end{array}$ & CIHI \\
\hline Neighbourhood Income Level & $\begin{array}{l}\text { Patient income quintiles, } \\
\text { based on neighbourhood } \\
\text { income from the } 1996 \text { (1992- } \\
1998 \text { patients), } 2001 \text { (1999- } \\
2004 \text { patients) and } 2006 \\
\text { (2005-2010 patients) census. }\end{array}$ & $\begin{array}{l}\text { 1996, } 2001 \text { and } 2006 \text { census } \\
\text { data }\end{array}$ \\
\hline
\end{tabular}




\begin{tabular}{|l|l|l|}
\hline Overall Mortality & $\begin{array}{l}\text { Death after index event } \\
\text { (regardless of cause) }\end{array}$ & RPDB \\
\hline Post-operative Recurrences & $\begin{array}{l}\text { Recurrence of inguinal hernia } \\
\text { following index event }\end{array}$ & OHIP and CIHI \\
\hline
\end{tabular}

*RPDB - Registered Person's Database

CIHI - Canadian Institute of Health Information discharge abstract database OHIP - Ontario Health Insurance Plan

(ICES Intranet 2011)

\section{Validation}

The validity of CIHI inguinal hernia codes can be confirmed through prior abstraction studies. A study commissioned by the Ontario Ministry of Health and Long Term Care to assess the accuracy of coding at CIHI provides additional evidence that hernia codes in CIHI are accurate (Juurlink and Croxford, 2005, Institutes for Clinical Evaluative Sciences).

In this study, a review of 1500 hospital charts were completed by trained abstractors and comparisons between previously recorded information and the re-abstracted CIHI codes were made. A high degree of agreement with previous recorded information was reported by the reabstractors, thus conforming the validity of CIHI codes. All codes were based on the ICD-10 coding system, however, the codes for inguinal hernia in ICD-9 are similar to those found in ICD-10. Therefore, the abstraction study results would be applicable to the ICD-9 system for inguinal hernia as well. 


\section{3: STUDY POPULATION}

Patients aged 18 to 90, who underwent primary inguinal hernia surgery in Ontario, Canada between January 1, 1993 and March 31, 2011 were identified from the Canadian Institute for Health Information Discharge Abstract Database (CIHI-DAD) using Canadian Classification of Diagnostic, Therapeutic and Surgical Procedures (CCP) and Canadian Classification of Health Interventions (CCI) procedure codes (from 1993-2002 CCP; from 2003-2010 CCI) .

Patients who underwent primary inguinal hernia repair were also identified through the Ontario Health Insurance Plan (OHIP) physicians billing database through billing code S323 (inguinal hernia repair); this code indicates a non-recurrent and non-emergency, elective, primary inguinal hernia surgery performed by a licensed surgeon in Ontario for a patient who has active health insurance coverage via OHIP. The OHIP billing database contains claims-based information from health providers which can be associated with treatment at specific treatment centres/hospitals via original institution numbers, as can be the records from CIHI-DAD.

The data from both the above mentioned sources was linked to ensure appropriate reliability and accuracy of records. This cohort was the followed longitudinally over time to determine which patients underwent surgical repair for a recurrent inguinal hernia (the outcome event, as discussed further in section 2.8: Outcomes). 


\section{Exclusions}

Excluded from analyses were records of persons younger than 18 or older than 90 years of age at the time of the index event, as well as records with missing information for patient identification or treating institute. Accurate information for the treating institute was vital for inclusion in the study since patients could not be assigned into hospital volume quartiles without this information.

Patients were also excluded if the following OHIP codes were linked to their records: S345 (massive inguinal hernia), S329/S330 (strangulated/incarcerated hernia), or if they underwent emergency inguinal hernia repair, identified via after hours emergency OHIP codes E409 (afterhours emergency between 5 pm and $12 \mathrm{am}$ ) and E410 (after-hours emergency between 12 am and $7 \mathrm{am})$. (See - Section 2.6: Outcomes).

\section{4: EXPOSURES}

The main exposure of interest for this study was hospital volume; specifically, whether treatment was at a general hospital or if it occurred at the Shouldice Hospital. Secondary exposures include various variables such as sex, age, income status, comorbidity score, LHIN, rural/urban status.

Hospital volume was defined as the number of inguinal hernia surgeries performed at an institution in the year prior to the index event. Hospitals were identified by using CIHI-DAD 
and OHIP institution unique identifiers. Patients undergoing treatment for inguinal hernia at general hospitals in Ontario during the study period were divided into quartiles based on hospital volume (quartile 1 indicating lowest volume, quartile 2 indicating mid-low volume, quartile 3 indicating mid-high volume, and quartile 4 indicating the highest volume general hospital for primary inguinal hernia repair).

Shouldice hospital, which is a high volume specialty hernia hospital in Toronto, Ontario, was categorized separately. There were approximately an equal number of patients in each of the general hospital quartiles. However, since Shouldice Hospital is exclusively a hernia treatment hospital, the number of patients in this group was slightly higher than in the general hospital quartiles.

An alternative analysis, to observe the effect of dividing patients who had treatment at general hospitals into terciles, as opposed to quartiles, while categorizing Shouldice Hospital separately, was also conducted, to observe if there were any observable differences in outcomes when hospital volume is defined differently. In this analysis, tercile 1 indicated lowest volume, tercile 2 indicated mid-volume and tercile 3 indicated treatment at the highest volume general hospitals. 


\section{5: COVARIATES}

Several confounding variables which may influence inguinal hernia recurrence were identified and controlled for during analyses. Patient level factors included age groups (ages 18-24, 25-34, 35-44, 45-54, 55-64, 65-74, 75-84, 85+), sex, comorbidity (CADG score 1-12) and neighbourhood income level (Quintile 1 (lowest) to Quintile 5 (highest)). Burden due to comorbid diseases was measured using the Johns Hopkins' Aggregated Diagnosis Groups (ADGs) categories. The 34 ADG categories were organized via software algorithms to produce 12 Collapsed ADGs (also known as CADGs), which were then used as categorical variables to adjust for within the model (80).

Johns Hopkins' Aggregated Diagnosis Groups (ADGs) categorical information to assess patient comorbidity was derived based on CIHI DAD International Classification of Diseases (ICD) diagnostic codes from each patient's index admission and from any hospital admissions in the year prior to primary inguinal hernia surgery. Further information regarding ADGs and Collapsed adjusted clinical groups (CADGs) is displayed in the following table (81). The John Hopkin's Case Mix system was preferred over a Charlson score as we wished to capture even those individuals who are low burden users of healthcare services. CADGs were presented as a summated score to show variations between patient categories. 


\begin{tabular}{|c|c|c|}
\hline \multicolumn{3}{|l|}{ Acute: } \\
\hline Minor & $\begin{array}{l}\text { Non-infectious gastroenteritis } \\
\text { Diaper or napkin rash } \\
\text { Unspecified viral infection } \\
\text { Croup }\end{array}$ & $\begin{array}{l}\text { Neck sprain } \\
\text { Injury to trunk } \\
\text { Headache } \\
\text { Pain in limb }\end{array}$ \\
\hline Major & $\begin{array}{l}\text { Phlebitis of lower extremities } \\
\text { Impaction of intestine } \\
\text { Hepatitis, unspecified } \\
\text { Pyogenic arthritis }\end{array}$ & $\begin{array}{l}\text { Intercranial injury } \\
\text { Poisoning by cardiotonic glycosides (or } \\
\text { similar drugs) } \\
\text { Cardiomegaly } \\
\text { Syncope and collapse }\end{array}$ \\
\hline Likely to recur & $\begin{array}{l}\text { Allergic rhinitis (cause unspecified) } \\
\text { Urticaria (unspecified) } \\
\text { Gout (unspecified) } \\
\text { Backache (unspecified) } \\
\text { Chronic tonsillitis }\end{array}$ & $\begin{array}{l}\text { Urinary tract infection } \\
\text { Viral wart } \\
\text { Nevus (non-neoplastic) } \\
\text { Inguinal hernia (NOS) } \\
\text { Sebaceous cyst }\end{array}$ \\
\hline Asthma & Extrinsic asthma & Intrinsic asthma \\
\hline $\begin{array}{l}\text { Chronic } \\
\text { medical: }\end{array}$ & & \\
\hline unstable & $\begin{array}{l}\text { Adult-onset Type II diabetes (with } \\
\text { ketoacidosis) } \\
\text { Cerebral thrombosis } \\
\text { Sickle-cell anaemia }\end{array}$ & $\begin{array}{l}\text { Malignant neoplasm of breast } \\
\text { Hodgkin's disease, unspecified type } \\
\text { Cystic fibrosis }\end{array}$ \\
\hline stable & $\begin{array}{l}\text { Adult-onset Type I diabetes } \\
\text { Essential hypertension }\end{array}$ & $\begin{array}{l}\text { Hypertrophy of breast } \\
\text { Localised adiposity }\end{array}$ \\
\hline
\end{tabular}




\begin{tabular}{|l|l|l|}
\hline $\begin{array}{l}\text { Chronic } \\
\text { specialty: }\end{array}$ & \multicolumn{2}{|l|}{} \\
\hline unstable & $\begin{array}{l}\text { Spinal stenosis of lumbar region } \\
\text { Osteochrondritis dissecans } \\
\text { Chronic mastoiditis }\end{array}$ & $\begin{array}{l}\text { Meniere's disease } \\
\text { Unspecified glaucoma } \\
\text { Scleritis/episcleritis }\end{array}$ \\
\hline stable & $\begin{array}{l}\text { Cervical spondylosis without } \\
\text { myelopathy } \\
\text { Other joint derangement }\end{array}$ & $\begin{array}{l}\text { Central hearing loss } \\
\text { Cholesteatoma }\end{array}$ \\
\hline Eye/dental & $\begin{array}{l}\text { Myopia } \\
\text { Unspecified disorder of conjunctiva }\end{array}$ & $\begin{array}{l}\text { Dental caries } \\
\text { Chronic gingivitis }\end{array}$ \\
\hline Psychosocial & $\begin{array}{l}\text { Cannabis abuse (unspecified) } \\
\text { Brief depressive reaction } \\
\text { Panic disorder }\end{array}$ & $\begin{array}{l}\text { Bulimia } \\
\text { Catatonic schizophrenia } \\
\text { Alcohol withdrawal delirium tremens }\end{array}$ \\
\hline $\begin{array}{l}\text { Prevention/admi } \\
\text { nistrative }\end{array}$ & $\begin{array}{l}\text { Routine infant or child health check } \\
\text { Pregnancy }\end{array}$ & $\begin{array}{l}\text { Pregnant state } \\
\text { Gynalocological examination }\end{array}$ \\
\hline
\end{tabular}

* Adapted from: Carlsson L, Borjesson U, Edgren L. Patient based 'burden-of-illness' in swedish primary health care. applying the johns hopkins ACG case-mix system in a retrospective study of electronic patient records. Int J Health Plann Manage. 2002 Jul-Sep;17(3):269-82.

Other covariates for which information was included in the database included rural or urban location of patients, as well as information about which LHIN (Local Health Integration Network) in Ontario they received treatment in. However, these variables were not included in the regression models, although univariate analyses were completed in detail. 
Median annual income in neighborhood of residence was determined using 1996, 2001 and 2006 census data (the 1996 census was referenced for patients who had hernia surgeries between 1993 and 1998, the 2001 census for those who had surgeries between 1999 and 2004, and the 2006 census data for those who had surgeries between 2005 and 2010), linked to postal forward sortation areas and categorized into community-specific quintiles within census regions (the lowest quintile indicating the lowest income levels, highest quintile representing those with the highest income).

\section{6: OUTCOMES}

The primary outcome of interest was defined as surgical repair for a recurrent inguinal hernia following the index event, as recurrence is one of the most commonly reported long term postsurgical complications after primary repair. Although infection and death are also possible, these complications are uncommon and recurrence of hernia is reported much more often. Access to administrative data sources allowed for the measurement of recurrence rates from real patient data. Recurrence events were identified via OHIP fee codes E725 (recurrent hernia) or E726 (repeat recurrent inguinal hernia) billed alongside any of the following: S323 (inguinal hernia repair), S345 (massive sliding inguinal hernia), S329 (strangulated without resection) or S330 (strangulated with resection). 
Those individuals who underwent primary emergency hernia repair were also not included as outlined in section 2.5 (Sub-section: Exclusions) as emergency hernia repairs were not considered to be the outcome of interest for this study. The aim of our study was to compare similar types of procedures, and some hospitals (general hospital facilities) are more likely to treat emergency or complicated hernias. Risk of recurrence is known to be increased for patients with such complicated cases, so our study focused on comparing non-emergency and noncomplicated cases from general hospitals with similar surgeries conducted at Shouldice Hospital. Our study measured surgical repair for a recurrent hernia and not necessarily the fact of recurrence, as there may be recurrent cases for which surgical repair was not completed.

\section{7: STATISTICAL ANALYSES}

Baseline comparisons across quartiles were made using $\chi^{2}$-test for categorical variables; the effect of hospital volume on hernia recurrence rates was determined using adjusted logistic regression and Cox proportional hazards regression (also known as time to event regression). Both models allowed for adjustment for any confounding variables: age, sex, income quintiles and CADG categories (1-12). Goodness of fit for the logistic regression model was determined via the Hosmer-Lemeshow test, with $\mathrm{p}$ values $>0.05$ indicating adequate model fitting (82).

The Cox proportional hazards model allowed for the estimation of time between the date of the index treatment and the date of the first hernia recurrence, death, or March 31, 2011, the maximum follow-up date. A minimal follow-up period of 3 years was thereby ensured for all 
patients. All statistical analyses were completed using SAS software version 9.2 (SAS Institute Inc, North Carolina). 2-tailed P-values less than 0.05 were considered statistically significant for all analyses $(83,84)$. The proportional hazards assumption was tested via visual inspection of Kaplan-Meier curves.

\section{8: ADDITIONAL ANALYSES}

\section{Sensitivity Analyses}

We performed a sensitivity analysis reproducing the Cox proportional hazards model with only the healthiest patients included in the cohort. Only those persons who had a low CADG score were used for comparison, indicating those individuals who were in good health. This approach was used to eliminate potentially unmeasured confounding.

A second sensitivity analysis was completed to observe the effect of treatment year on outcomes; this variable was not included directly in the regression model. This analysis was completed by limiting the cohort initially to include only observations between 1993-2000 and then between 2001-2007. This allowed us to evaluate the changing trends in inguinal hernia surgery repair techniques.

\section{Stratified Analysis}

The overall performance of Shouldice Hospital, as compared to general hospitals in Ontario across various covariate sub-groups was completed by collapsing all general hospital categories into one, and making comparisons with Shouldice Hospital. 
This allowed for the evaluation of how Shouldice Hospital performed when compared with general hospital in Ontario in younger vs. older patients, males vs. females, treatment during early period (1993-2000) vs. late period (2001-2007), low income vs. high income, low comorbidity vs. high comorbidity, and also overall how Shouldice Hospital compared to general hospitals. Interaction terms (Shouldice*various predictor variables) were used to generate Pvalues to indicate significant and non-significant variations across variables.

\section{Shouldice Hospital Patient Selection}

Lastly, an analysis was completed to observe what effect, if any, patient selection factors at Shouldice hospital had on the type of patients who were operated on at Shouldice Hospital. To evaluate this, the following steps were followed:

1) Surgeons operating at Shouldice hospital between 2004-2006 were identified.

2) Patients of the surgeons identified above, for whom OHIP initial consultation billing codes A035, A935, C035, C935 (with a diagnosis for inguinal hernia associated with these codes) were identified.

3) Of these patients who had consultations with Shouldice surgeons, it was determined how many had hernia surgery (S323 - primary non-recurrent inguinal hernia repair) in the year after their initial consultation (counting 1 year after the initial consult for each patient). 
The aim of this analysis specifically was to discover how many patients had surgery at Shouldice and how many had surgery at some other institute. This in turn allowed us to understand how significant of an effect patient selection factors had on outcomes observed at Shouldice hospital.

\section{Outcomes at Teaching Hospitals}

Teaching hospitals may differ from other hospitals with respect to processes of care and outcomes. A sub-analysis to compare outcomes of patients who had treatment at various teaching hospitals in Ontario was completed. The purpose of this exercise was to identify if there is a significant benefit associated with treatment at a specific type of teaching hospital (high volume vs. low volume).

\section{9: ETHICS STATEMENT}

The protocol for this study was approved by the research ethics board of Sunnybrook Health Sciences Centre, Toronto, Ontario, Canada. Data collection and analysis was completed after ethics approval. All records used were uniquely labeled using encrypted health card numbers. No unique identifiers such as patient name, OHIP number, postal code or address were recorded or made available to the researchers involved. 


\section{CHAPTER 3: RESULTS}

\section{1: PATIENT AND HOSPITAL BASELINE DEMOGRAPHICS}

From January 1, 1993 to December 31, 2007, the total number of hernia surgeries performed in the province of Ontario was 379,749 ; this number was reduced to 235,192 , which was the number of persons eligible for inclusion in the study after exclusions were made. A flowchart summary of the exclusion codes used to identify the final cohort of patients is displayed in Figure 3.1.

Figure 3.1: Hernia volume-outcome study exclusions

\begin{tabular}{|l|l|}
\hline - Total hernia surgeries performed in study period & - Exclude: S345 (Massive inguinal hernia) \\
\hline - Exclude: S329 (Strangulated/Incarcerated Hernia) & - Exclude: S330 (Strangulated/Incarcerated Hernia) \\
\hline - Exclude: E409 (After-hours emergency) & \\
\hline - Exclude: E410 (After-hours emergency) & \\
\hline - Other exclusions: Invalid IKN, missing Institute Number, age $<18$ or $>90$ years, morbid \\
obesity
\end{tabular}


A breakdown of the number of cases, recurrences, volume cut-points as well as crude and age standardized recurrence rates, organized by quartile of hospital volume is provided in Table 3.1. Of the 235,192 primary inguinal hernia repairs performed in Ontario during the study period, 170,065 patients had their surgeries at general hospitals, and 65,127 surgeries were performed at the Shouldice Hospital.

The high number of procedures completed at Shouldice (almost 30\% of the total eligible number of procedures) is a result of Shouldice Hospital being a hernia exclusive hospital. Compared to general hospital categories, Shouldice hospital treated a higher proportion of males, fewer individuals from low income households and also fewer individuals with high burden due to comorbidity.

The highest volume general hospitals, which would be expected to be present in urban centers, had a lower number of patients from rural communities. Corresponding to this, more patients from rural communities were treated at low volume general hospitals within their local communities. 


\begin{tabular}{|c|c|c|c|c|c|c|}
\hline & \multicolumn{4}{|c|}{ General Hospitals in Ontario } & \multirow[b]{2}{*}{ Shouldice } & \multirow[b]{2}{*}{ Overall } \\
\hline & 1 (Lowest) & 2 & 3 & $\begin{array}{c}4 \\
\text { (Highest) }\end{array}$ & & \\
\hline $\begin{array}{l}\text { Number of } \\
\text { Subjects }\end{array}$ & 42,427 & 42,644 & 42,346 & 42,648 & 65,127 & 235,192 \\
\hline $\begin{array}{l}\text { Median Volume } \\
\text { (Range) }\end{array}$ & $\begin{array}{c}61 \\
(1-106)\end{array}$ & $\begin{array}{c}142 \\
(107- \\
185)\end{array}$ & $\begin{array}{c}219 \\
(186- \\
267)\end{array}$ & $\begin{array}{c}341 \\
(268-803)\end{array}$ & $\begin{array}{c}5672 \\
(5103-5888)\end{array}$ & - \\
\hline Median Age & 57 & 56 & 56 & 55 & 54 & 55 \\
\hline Males (\%) & 88.5 & 88.3 & 88.4 & 89.4 & 94.5 & 90.3 \\
\hline Low Income (\%) & 60.8 & 60.9 & 60.2 & 56.8 & 48.2 & 56.5 \\
\hline $\begin{array}{c}\text { High } \\
\text { Comorbidity }(\%)\end{array}$ & 27.6 & 29.9 & 30.8 & 30.1 & 23.3 & 27.8 \\
\hline Rural (\%) & 42.2 & 15.6 & 8.7 & 6.2 & 9.7 & 15.8 \\
\hline
\end{tabular}

Baseline information for the entire cohort, divided into quartiles of hospital volume, is presented in Table 3.2. This table shows that the patient population was predominantly male, which is an anticipated result since inguinal hernias occur primarily in males. Also, majority of the patients were middle aged there were no significant variations across age groups when comparing all general hospital quartiles with Shouldice hospital. 
Shouldice Hospital tended to treat a higher number of patients in the highest income quintile and most patients treated at Shouldice came from urban areas. Furthermore, most patients were living in urban areas, across the various hospital volume groups.

Table 3.2: Patient level variables by hospital volume and type. Hernia surgery volume increases with quartiles. Values listed are counts (percentages). Patient level variables are determined based on the full cohort of 235,192 patients. $\mathrm{P}$ values reflect comparisons across quartiles. Column percentages may not add up 100 due to rounding.

\begin{tabular}{|c|c|c|c|c|c|c|c|}
\hline \multirow[b]{2}{*}{ Variable } & \multicolumn{5}{|c|}{ Hospital Volume } & \multirow[b]{2}{*}{$\begin{array}{c}\text { Full } \\
\text { Cohort } \\
(\mathrm{N}=\mathbf{2 3 5 1 9 2})\end{array}$} & \multirow[b]{2}{*}{ P-value } \\
\hline & $\begin{array}{c}\text { Quartile 1 } \\
(\mathrm{N}=\mathbf{4 2 , 4 2 7 )}\end{array}$ & $\begin{array}{l}\text { Quartile } 2 \\
(\mathrm{~N}=42,644)\end{array}$ & $\begin{array}{l}\text { Quartile } 3 \\
(\mathrm{~N}=42,346)\end{array}$ & $\begin{array}{c}\text { Quartile } 4 \\
(\mathrm{~N}=42,648)\end{array}$ & $\begin{array}{l}\text { Shouldice } \\
(\mathrm{N}=65,127)\end{array}$ & & \\
\hline \multicolumn{7}{|c|}{ Age Group } & $<0.0001$ \\
\hline $18-24$ & $\begin{array}{c}2326 \\
(5.5 \%)\end{array}$ & $\begin{array}{c}2227 \\
(5.2 \%)\end{array}$ & $\begin{array}{c}2049 \\
(4.8 \%)\end{array}$ & $2071(4.9 \%)$ & $\begin{array}{c}2822 \\
(4.3 \%)\end{array}$ & $\begin{array}{l}11495 \\
(4.9 \%)\end{array}$ & \\
\hline $25-34$ & $\begin{array}{c}3897 \\
(9.2 \%)\end{array}$ & $\begin{array}{c}3977 \\
(9.3 \%)\end{array}$ & $\begin{array}{c}3820 \\
(9.0 \%)\end{array}$ & $3946(9.3 \%)$ & $\begin{array}{c}5646 \\
(8.7 \%)\end{array}$ & $\begin{array}{l}21286 \\
(9.1 \%)\end{array}$ & \\
\hline $35-44$ & $\begin{array}{c}6178 \\
(14.6 \%)\end{array}$ & $\begin{array}{c}6351 \\
(14.9 \%)\end{array}$ & $\begin{array}{c}6482 \\
(15.3 \%)\end{array}$ & $\begin{array}{c}6722 \\
(15.8 \%)\end{array}$ & $\begin{array}{c}10453 \\
(16.1 \%)\end{array}$ & $\begin{array}{c}36186 \\
(15.4 \%)\end{array}$ & \\
\hline $45-54$ & $\begin{array}{c}7178 \\
(16.9 \%)\end{array}$ & $\begin{array}{c}7627 \\
(17.9 \%)\end{array}$ & $\begin{array}{c}7750 \\
(18.3 \%)\end{array}$ & $\begin{array}{c}8272 \\
(19.4 \%)\end{array}$ & $\begin{array}{c}13946 \\
(21.4 \%)\end{array}$ & $\begin{array}{c}44773 \\
(19.0 \%)\end{array}$ & \\
\hline $55-64$ & $\begin{array}{c}7860 \\
(18.5 \%)\end{array}$ & $\begin{array}{c}7990 \\
(18.7 \%)\end{array}$ & $\begin{array}{c}8006 \\
(18.9 \%)\end{array}$ & $\begin{array}{c}8411 \\
(19.7 \%)\end{array}$ & $\begin{array}{c}14783 \\
(22.7 \%)\end{array}$ & $\begin{array}{c}47050 \\
(20.0 \%)\end{array}$ & \\
\hline $65-74$ & $\begin{array}{c}8647 \\
(20.4 \%)\end{array}$ & $\begin{array}{c}8182 \\
(19.2 \%)\end{array}$ & $\begin{array}{c}8083 \\
(19.1 \%)\end{array}$ & $\begin{array}{c}7815 \\
(18.3 \%)\end{array}$ & $\begin{array}{c}11932 \\
(18.3 \%)\end{array}$ & $\begin{array}{c}44659 \\
(19.0 \%)\end{array}$ & \\
\hline $75-84$ & $\begin{array}{c}5451 \\
(12.9 \%)\end{array}$ & $\begin{array}{c}5447 \\
(12.8 \%)\end{array}$ & $\begin{array}{c}5331 \\
(12.6 \%)\end{array}$ & $\begin{array}{c}4739 \\
(11.1 \%)\end{array}$ & $\begin{array}{c}4981 \\
(7.7 \%)\end{array}$ & $\begin{array}{c}25949 \\
(11.0 \%)\end{array}$ & \\
\hline $85+$ & 890 & $843(2.0 \%)$ & $825(2.0 \%)$ & $672(1.6 \%)$ & $564(0.9 \%)$ & 3794 & \\
\hline
\end{tabular}




\begin{tabular}{|c|c|c|c|c|c|c|c|}
\hline & $(2.1 \%)$ & & & & & $(1.6 \%)$ & \\
\hline \multicolumn{7}{|c|}{ Sex } & $<0.0001$ \\
\hline Males & $\begin{array}{c}37529 \\
(88.5 \%)\end{array}$ & $\begin{array}{c}37657 \\
(88.3 \%)\end{array}$ & $\begin{array}{c}37450 \\
(88.4 \%)\end{array}$ & $\begin{array}{c}38109 \\
(89.4 \%)\end{array}$ & $\begin{array}{c}61572 \\
(94.5 \%)\end{array}$ & $\begin{array}{l}212317 \\
(90.3 \%)\end{array}$ & \\
\hline Females & $\begin{array}{c}4898 \\
(11.5 \%)\end{array}$ & $\begin{array}{c}4987 \\
(11.7 \% 0\end{array}$ & $\begin{array}{c}4896 \\
(11.6 \%)\end{array}$ & $\begin{array}{c}4539 \\
(10.6 \%)\end{array}$ & $\begin{array}{c}3555 \\
(5.5 \%)\end{array}$ & $\begin{array}{l}22875 \\
(9.7 \%)\end{array}$ & \\
\hline \multicolumn{7}{|c|}{ Comorbidity } & $<0.0001$ \\
\hline Low & $\begin{array}{c}14379 \\
(33.9 \%)\end{array}$ & $\begin{array}{c}13765 \\
(32.3 \%)\end{array}$ & $\begin{array}{c}12858 \\
(30.4 \%)\end{array}$ & $\begin{array}{c}13180 \\
(30.9 \%)\end{array}$ & $\begin{array}{c}24329 \\
(37.4 \%)\end{array}$ & $\begin{array}{c}78511 \\
(33.4 \%)\end{array}$ & \\
\hline Mid & $\begin{array}{c}26151 \\
(61.6 \%)\end{array}$ & $\begin{array}{c}26675 \\
(62.6 \%)\end{array}$ & $\begin{array}{c}27141 \\
(64.1 \%)\end{array}$ & $\begin{array}{c}27122 \\
(63.6 \%)\end{array}$ & $\begin{array}{c}38465 \\
(59.1 \%)\end{array}$ & $\begin{array}{l}145554 \\
(61.9 \%)\end{array}$ & \\
\hline High & $\begin{array}{c}1897 \\
(4.5 \%)\end{array}$ & $\begin{array}{l}2204 \\
(5.2 \%)\end{array}$ & $\begin{array}{c}2347 \\
(5.5 \%)\end{array}$ & $2346(5.5 \%)$ & $\begin{array}{c}2333 \\
(3.6 \%)\end{array}$ & $\begin{array}{l}11127 \\
(4.7 \%)\end{array}$ & \\
\hline \multicolumn{7}{|c|}{ Income Level (Quintiles) } & $<0.0001$ \\
\hline Q 1 & $\begin{array}{c}7977 \\
(19.0 \%)\end{array}$ & $\begin{array}{c}8340 \\
(19.7 \%)\end{array}$ & $\begin{array}{c}8101 \\
(19.2 \%)\end{array}$ & $\begin{array}{c}7396 \\
(17.4 \%)\end{array}$ & $\begin{array}{c}8198 \\
(12.7 \%)\end{array}$ & $\begin{array}{c}40012 \\
(17.1 \%)\end{array}$ & \\
\hline Q 2 & $\begin{array}{c}8878 \\
(21.1 \%)\end{array}$ & $\begin{array}{c}8832 \\
(20.8 \%)\end{array}$ & $\begin{array}{c}8594 \\
(20.4 \%)\end{array}$ & $\begin{array}{c}8210 \\
(19.3 \%)\end{array}$ & $\begin{array}{c}10698 \\
(16.5 \%)\end{array}$ & $\begin{array}{c}45212 \\
(19.3 \%)\end{array}$ & \\
\hline Q 3 & $\begin{array}{c}8709 \\
(20.7 \%)\end{array}$ & $\begin{array}{c}8673 \\
(20.5 \%)\end{array}$ & $\begin{array}{c}8673 \\
(20.56 \%)\end{array}$ & $\begin{array}{c}8534 \\
(20.1 \%)\end{array}$ & $\begin{array}{c}12375 \\
(19.1 \%)\end{array}$ & $\begin{array}{c}46964 \\
(20.1 \%)\end{array}$ & \\
\hline Q 4 & $\begin{array}{c}8565 \\
(20.4 \%)\end{array}$ & $\begin{array}{c}8474 \\
(20.0 \%)\end{array}$ & $\begin{array}{c}8314 \\
(19.7 \%)\end{array}$ & $\begin{array}{c}8859 \\
(20.9 \%)\end{array}$ & $\begin{array}{c}14519 \\
(22.4 \%)\end{array}$ & $\begin{array}{c}48731 \\
(20.8 \%)\end{array}$ & \\
\hline Q 5 & $\begin{array}{c}7910 \\
(18.8 \%)\end{array}$ & $\begin{array}{c}8067 \\
(19.0 \%)\end{array}$ & $\begin{array}{c}8494 \\
(20.1 \%)\end{array}$ & $\begin{array}{c}9472 \\
(22.3 \%)\end{array}$ & $\begin{array}{c}19034 \\
(29.4 \%)\end{array}$ & $\begin{array}{c}52977 \\
(22.7 \%)\end{array}$ & \\
\hline \multicolumn{7}{|c|}{ Rural/Urban Status } & $<0.0001$ \\
\hline Urban & $\begin{array}{c}24468 \\
(57.8 \%)\end{array}$ & $\begin{array}{c}35928 \\
(84.4 \%)\end{array}$ & $\begin{array}{c}38596 \\
(91.3 \%)\end{array}$ & $\begin{array}{c}39919 \\
(93.8 \%)\end{array}$ & $\begin{array}{c}58655 \\
(90.3 \%)\end{array}$ & $\begin{array}{l}197566 \\
(84.2 \%)\end{array}$ & \\
\hline Rural & $\begin{array}{c}17866 \\
(42.2 \%)\end{array}$ & $\begin{array}{c}6632 \\
(15.6 \%)\end{array}$ & $\begin{array}{c}3687 \\
(8.7 \%)\end{array}$ & $2652(6.2 \%)$ & $\begin{array}{c}6319 \\
(9.7 \%)\end{array}$ & $\begin{array}{c}37156 \\
(15.8 \%)\end{array}$ & \\
\hline
\end{tabular}




\section{2: RECURRENCE RATES}

A total of 9020 inguinal hernia recurrences were treated surgically during the study period, as defined by the criteria for this study. Recurrence statistics are shown in Table 3.3 The risk of recurrence in the lowest volume quartile was 5.2 (95\% CI $4.9 \%$ to5.5\%), as compared to 4.8 (4.5\% to $5.0 \%)$ at high volume general hospitals and $1.2(1.1 \%$ to $1.3 \%)$ at the Shouldice hospital.

There was a trend across the various volume quartiles that clearly showed an association between higher procedural volume and better outcomes for patients (with the exception of mid-low and lowest volume categories, which displayed a slight inconsistency in terms of expected volumeoutcome relationships).

\begin{tabular}{|c|c|c|c|c|c|c|}
\hline \multicolumn{7}{|c|}{ Table 3.3: Recurrence Statistics according to hospital volume and type } \\
\hline & \multicolumn{4}{|c|}{ General Hospitals in Ontario } & \multirow[t]{2}{*}{ Shouldice } & \multirow[t]{2}{*}{ Overal } \\
\hline & 1 (Lowest) & 2 & 3 & 4 (Highest) & & \\
\hline $\begin{array}{c}\text { Number of } \\
\text { Subjects }\end{array}$ & 42,427 & 42,644 & 42,346 & 42,648 & 65,127 & 235,192 \\
\hline $\begin{array}{l}\text { Number of } \\
\text { Recurrences }\end{array}$ & 2163 & 2320 & 1916 & 1920 & 701 & 9020 \\
\hline
\end{tabular}




\begin{tabular}{|c|c|c|c|c|c|c|}
\hline $\begin{array}{c}\text { Incidence } \\
\text { Rate } \\
(/ 1000 \text { PY) }\end{array}$ & 5.68 & 6.30 & 5.32 & 4.97 & 1.07 & 4.27 \\
\hline Crude Rate & 5.10 & 5.44 & 4.52 & 4.50 & 1.08 & 3.84 \\
\hline $\begin{array}{c}\text { Age- } \\
\text { Standardized } \\
\text { Rate }(\mathrm{CI})\end{array}$ & $\begin{array}{c}5.21 \\
(4.94-5.49)\end{array}$ & $\begin{array}{c}5.63 \\
(5.35-5.91)\end{array}$ & $\begin{array}{c}4.90 \\
(4.64-5.17)\end{array}$ & $\begin{array}{c}4.79 \\
(4.54-5.04)\end{array}$ & $\begin{array}{c}1.15 \\
(1.05-1.25)\end{array}$ & $\begin{array}{c}3.95 \\
(3.86-4.05)\end{array}$ \\
\hline
\end{tabular}

Baseline information for the subset of the cohort that represented cases with recurrent hernias, displayed by hospital volume and type, is presented in Table 3.4. Lower volume hospitals had higher recurrence rates when compared to the high volume hospitals; the most interesting comparison is between the high volume general hospital recurrence rates and the Shouldice Hospital. Across all variables, recurrence rates at Shouldice hospital were consistently lower when compared to general hospitals in Ontario. 
Table 3.4: Patient level variables by hospital volume and type (Recurrences). Hernia surgery volume increases with quartiles. Values listed are counts (percentages). Patient level variables are determined based on the total number of recurrences (9020). P-values reflect comparisons across quartiles. (Cells with values $<5$ have been replaced with an asterisk as per ICES privacy protocols). Column percentages may not add up 100 due to rounding.

\begin{tabular}{|c|c|c|c|c|c|c|c|}
\hline \multirow[t]{2}{*}{ Variable } & \multicolumn{5}{|c|}{ Hospital Volume } & \multirow[b]{2}{*}{$\begin{array}{l}\text { Full } \\
\text { Cohort } \\
(\mathrm{N}=9020)\end{array}$} & \multirow[t]{2}{*}{ P-value } \\
\hline & $\begin{array}{l}\text { Quartile } 1 \\
(\mathrm{~N}=\mathbf{2 1 6 3})\end{array}$ & $\begin{array}{l}\text { Quartile } 2 \\
(\mathrm{~N}=\mathbf{2 3 2 0})\end{array}$ & $\begin{array}{l}\text { Quartile } 3 \\
(\mathrm{~N}=1916)\end{array}$ & $\begin{array}{l}\text { Quartile } 4 \\
(\mathrm{~N}=1920)\end{array}$ & $\begin{array}{l}\text { Shouldice } \\
(\mathrm{N}=701)\end{array}$ & & \\
\hline \multicolumn{7}{|c|}{ Age Group } & $<0.0001$ \\
\hline 18-24 & $93(4.3 \%)$ & $82(3.5 \%)$ & $57(3.0 \%)$ & $59(3.1 \%)$ & $12(1.7 \%)$ & $303(3.4 \%)$ & \\
\hline 25-34 & $197(9.1 \%)$ & $214(9.2 \%)$ & $154(8.0 \%)$ & $130(6.8 \%)$ & $27(3.9 \%)$ & $722(8.0 \%)$ & \\
\hline $35-44$ & $\begin{array}{c}317 \\
(14.7 \%)\end{array}$ & $\begin{array}{c}351 \\
(15.1 \%)\end{array}$ & $\begin{array}{c}307 \\
(16.0 \%)\end{array}$ & $\begin{array}{c}290 \\
(15.1 \%)\end{array}$ & $\begin{array}{c}105 \\
(15.0 \%)\end{array}$ & $\begin{array}{c}1370 \\
(15.2 \%)\end{array}$ & \\
\hline 45-54 & $\begin{array}{c}380 \\
(17.6 \%)\end{array}$ & $\begin{array}{c}452 \\
(19.5 \%)\end{array}$ & $\begin{array}{c}420 \\
(21.9 \%)\end{array}$ & $\begin{array}{c}413 \\
(21.5 \%)\end{array}$ & $\begin{array}{c}153 \\
(21.8 \%)\end{array}$ & $\begin{array}{c}1818 \\
(21.2 \%)\end{array}$ & \\
\hline $55-64$ & $\begin{array}{c}450 \\
(20.8 \%)\end{array}$ & $\begin{array}{c}480 \\
(20.7 \%)\end{array}$ & $\begin{array}{c}386 \\
(20.2 \%)\end{array}$ & $\begin{array}{c}435 \\
(22.7 \%)\end{array}$ & $\begin{array}{c}178 \\
(25.4 \%)\end{array}$ & $\begin{array}{c}1929 \\
(21.4 \%)\end{array}$ & \\
\hline $65-74$ & $\begin{array}{c}500 \\
(23.1 \%)\end{array}$ & $\begin{array}{c}505 \\
(21.8 \%)\end{array}$ & $\begin{array}{c}400 \\
(20.9 \%)\end{array}$ & $\begin{array}{c}413 \\
(21.5 \%)\end{array}$ & $\begin{array}{c}161 \\
(23.0 \%)\end{array}$ & $\begin{array}{c}1979 \\
(21.9 \%)\end{array}$ & \\
\hline $75-84$ & $211(9.8 \%)$ & $211(9.1 \%)$ & $173(9.0 \%)$ & $172(9.0 \%)$ & $64(9.1 \%)$ & $831(9.2 \%)$ & \\
\hline $85+$ & $15(0.7 \%)$ & $25(1.1 \%)$ & $19(1.0 \%)$ & $*(0.4 \%)$ & $*(0.1 \%)$ & $68(0.8 \%)$ & \\
\hline \multicolumn{7}{|c|}{ Sex } & $<0.0001$ \\
\hline Males & $\begin{array}{c}1963 \\
(90.8 \%)\end{array}$ & $\begin{array}{l}2122 \\
(91.5 \%)\end{array}$ & $\begin{array}{c}1715 \\
(89.5 \%)\end{array}$ & $\begin{array}{c}1753 \\
(91.3 \%)\end{array}$ & $\begin{array}{c}649 \\
(92.6 \%)\end{array}$ & $\begin{array}{c}8202 \\
(90.9 \%)\end{array}$ & \\
\hline Females & $200(9.3 \%)$ & $198(8.5 \%)$ & $\begin{array}{c}201 \\
(10.5 \%)\end{array}$ & $\begin{array}{c}167 \\
(8.7 \%)\end{array}$ & $52(7.4 \%)$ & $818(9.1 \%)$ & \\
\hline
\end{tabular}




\begin{tabular}{|c|c|c|c|c|c|c|c|}
\hline \multicolumn{7}{|c|}{ Comorbidity } & \multirow[t]{2}{*}{$<0.0001$} \\
\hline Low & $\begin{array}{l}706 \\
(32.6 \%)\end{array}$ & $\begin{array}{l}739 \\
(31.9 \%)\end{array}$ & $\begin{array}{c}609 \\
(31.8 \%)\end{array}$ & $\begin{array}{c}594 \\
(30.9 \%)\end{array}$ & $\begin{array}{c}203 \\
(29.0 \%)\end{array}$ & $\begin{array}{c}2851 \\
(31.6 \%)\end{array}$ & \\
\hline Mid & $\begin{array}{c}1363 \\
(63.0 \%)\end{array}$ & $\begin{array}{c}1466 \\
(63.2 \%)\end{array}$ & $\begin{array}{c}1212 \\
(63.3 \%)\end{array}$ & $\begin{array}{c}1228 \\
(64.0 \%)\end{array}$ & $\begin{array}{c}464 \\
(66.2 \%)\end{array}$ & $\begin{array}{c}5733 \\
(63.6 \%)\end{array}$ & \\
\hline High & $94(4.4 \%)$ & $115(5.0 \%)$ & $95(5.0 \%)$ & $98(5.1 \%)$ & $34(4.9 \%)$ & $436(4.8 \%)$ & \\
\hline \multicolumn{7}{|c|}{ Income Level (Quintiles) } & $<0.0001$ \\
\hline Q 1 & $\begin{array}{c}390 \\
(18.2 \%)\end{array}$ & $\begin{array}{c}441 \\
(19.2 \%)\end{array}$ & $\begin{array}{c}364 \\
(19.1 \%)\end{array}$ & $\begin{array}{c}353 \\
(18.5 \%)\end{array}$ & $95(13.7 \%)$ & $\begin{array}{c}1643 \\
(18.3 \%)\end{array}$ & \\
\hline Q 2 & $\begin{array}{c}470 \\
(21.9 \%)\end{array}$ & $\begin{array}{c}477 \\
(20.8 \%)\end{array}$ & $\begin{array}{c}384 \\
(20.1 \%)\end{array}$ & $\begin{array}{c}359 \\
(18.8 \%)\end{array}$ & $\begin{array}{c}115 \\
(16.5 \%)\end{array}$ & $\begin{array}{c}1805 \\
(20.2 \%)\end{array}$ & \\
\hline Q 3 & $\begin{array}{c}424 \\
(19.8 \%)\end{array}$ & $\begin{array}{c}469 \\
(20.4 \%)\end{array}$ & $\begin{array}{c}384 \\
(20.1 \%)\end{array}$ & $\begin{array}{c}331 \\
(17.3 \%)\end{array}$ & $\begin{array}{c}144 \\
(20.7 \%)\end{array}$ & $\begin{array}{c}1752 \\
(19.6 \%)\end{array}$ & \\
\hline Q 4 & $\begin{array}{c}455 \\
(21.2 \%)\end{array}$ & $\begin{array}{c}459 \\
(20.0 \%)\end{array}$ & $\begin{array}{c}393 \\
(20.6 \%)\end{array}$ & $\begin{array}{c}403 \\
(21.1 \%)\end{array}$ & $\begin{array}{c}152 \\
(21.8 \%)\end{array}$ & $\begin{array}{c}1862 \\
(20.8 \%)\end{array}$ & \\
\hline Q 5 & $\begin{array}{c}403 \\
(18.8 \%)\end{array}$ & $\begin{array}{c}453 \\
(19.7 \%)\end{array}$ & $\begin{array}{c}385 \\
(20.2 \%)\end{array}$ & $\begin{array}{c}467 \\
(24.4 \%)\end{array}$ & $\begin{array}{c}190 \\
(27.3 \%)\end{array}$ & $\begin{array}{c}1898 \\
(21.2 \%)\end{array}$ & \\
\hline \multicolumn{7}{|c|}{ Rural/Urban Status } & $<0.0001$ \\
\hline Urban & $\begin{array}{c}1330 \\
(61.6 \%)\end{array}$ & $\begin{array}{c}1990 \\
(85.9 \%)\end{array}$ & $\begin{array}{c}1730 \\
(90.3 \%)\end{array}$ & $\begin{array}{c}1802 \\
(94.0 \%)\end{array}$ & $\begin{array}{c}623 \\
(88.9 \%)\end{array}$ & $\begin{array}{c}7475 \\
(83.0 \%)\end{array}$ & \\
\hline Rural & $\begin{array}{c}830 \\
(38.4 \%)\end{array}$ & $\begin{array}{c}327 \\
(14.1 \%)\end{array}$ & $185(9.7 \%)$ & $\begin{array}{c}116 \\
(6.1 \%)\end{array}$ & $78(11.1 \%)$ & $\begin{array}{c}1536 \\
(17.1 \%)\end{array}$ & \\
\hline
\end{tabular}




\section{3: LOGISTIC REGRESSION}

Results from the logistic regression model, both crude and adjusted are presented in Table 3.5. The odds ratio and P-values for hospital volume suggested a trend towards improved outcomes at higher volume hospitals, with a significant benefit associated with treatment at Shouldice Hospital vs. high volume general hospitals.

The Hosmer-Lemeshow goodness of fit test was non-significant, indicating adequate model fitting $(\mathrm{P}=0.29)$. The trend in odds ratios, indicating a significant benefit associated with treatment at higher volume hospitals and especially at the specialty Shouldice Hospital was maintained even after adjustment for potential confounding variables, including: age group, sex, income level and CADG score.

Results showed an adjusted odds ratio of 0.88 for high volume general hospitals (referent to the lowest volume quartile). There was a significant difference observed for the odds ratio for Shouldice, which was 0.21 (also referent to the lowest volume general hospitals). 
Table 3.5: Logistic regression results - Unadjusted and adjusted for patient-level variables

\section{Unadjusted}

\begin{tabular}{|c|c|c|c|c|}
\hline \multicolumn{2}{|c|}{} & 95\% Confidence Interval & \\
\hline Hospital Category & Odds Ratio & Lower & Upper & P-value \\
\hline Lowest Volume & 1.00 & \multicolumn{2}{|c|}{ (Referent) } \\
\hline Mid-Low Volume & 1.07 & 1.01 & 1.14 & 0.03 \\
\hline Mid-High Volume & 0.88 & 0.83 & 0.94 & $<0.001$ \\
\hline Highest Volume & 0.88 & 0.82 & 0.94 & $<0.001$ \\
\hline Shouldice & 0.20 & 0.19 & 0.22 & $<0.001$ \\
\hline
\end{tabular}

Adjusted*

\begin{tabular}{|c|c|c|c|c|}
\hline \multicolumn{2}{|c|}{} & \multicolumn{2}{|c|}{$95 \%$ Confidence Interval } & Upper \\
\hline Variable & Odds Ratio & Lower & \multicolumn{2}{|c|}{ (Referent) } \\
\hline Lowest Volume & 1.00 & 1.00 & 1.13 & 0.05 \\
\hline Mid-Low Volume & 1.06 & 0.82 & 0.93 & $<0.001$ \\
\hline Mid-High Volume & 0.88 & 0.81 & 0.92 & $<0.001$ \\
\hline Shighest Volume & 0.86 & 0.18 & 0.21 & $<0.001$ \\
\hline
\end{tabular}

*Adjusted for: Age, Sex, Income Quintile, Comorbidity 


\section{4: TIME TO EVENT REGRESSION}

$\underline{\text { General Hospitals Divided into Quartiles }}$

Hospital volume was statistically significant in both unadjusted and adjusted Cox proportional hazards models; complete results are presented in Table 3.6. Compared to persons who had surgery at the lowest volume hospitals, hernia recurrence among persons who had their hernia repair at the Shouldice Hospital was substantially lower after adjustment for age group, sex, ADG score and income level (adjusted hazard ratio 0.20, (95\% CI 0.18 to 0.21 ), P <0.001). Compared to the lowest volume quartile, the adjusted hazard ratio for the highest volume quartile of general hospitals was $0.90,(95 \%$ CI 0.84 to 0.95$), \mathrm{P}<0.001$. An observation of interest was that the hazard ratios indicated that mid-low volume hospitals performed worse than low volume hospitals; the confidence interval and P-value associated with this observation however indicates that this observation is not significant.

Table 3.6: Risk of Hernia Recurrence by Hospital Volume and Type (Cox Regression - Quartiles)

\begin{tabular}{|c|c|c|c|}
\hline \multicolumn{5}{|c|}{ Cox Regression * } \\
\hline Hospital Category & Hazard Ratio & $\mathbf{9 5 \%}$ CI & P-Value \\
\hline Lowest Volume & 1.00 & \multicolumn{2}{|c|}{ (Referent) } \\
\hline Mid-Low Volume & 1.11 & $(1.04-1.17)$ & $<0.001$ \\
\hline Mid-High Volume & 0.95 & $(0.89-1.01)$ & 0.09 \\
\hline Highest Volume & 0.90 & $(0.84-0.95)$ & $<0.001$ \\
\hline Shouldice & 0.20 & $(0.18-0.21)$ & $<0.001$ \\
\hline
\end{tabular}

*Adjusted for: Age, Sex, Income Quintile, Comorbidity 
The curves in Figure 3.2 represent the comparison across quartiles over the study period. The regression model did not account for year of treatment or for specific comorbidities. These Kaplan-Meier curves indicate the probability of recurrence across the time-period of the study; the difference between probability of recurrence at general hospital categories and Shouldice hospital is significant. The proportional hazards assumption was upheld according to the curves shown below.

Figure 3.2: Probability of Recurrence By Hospital Volume (Quartiles)

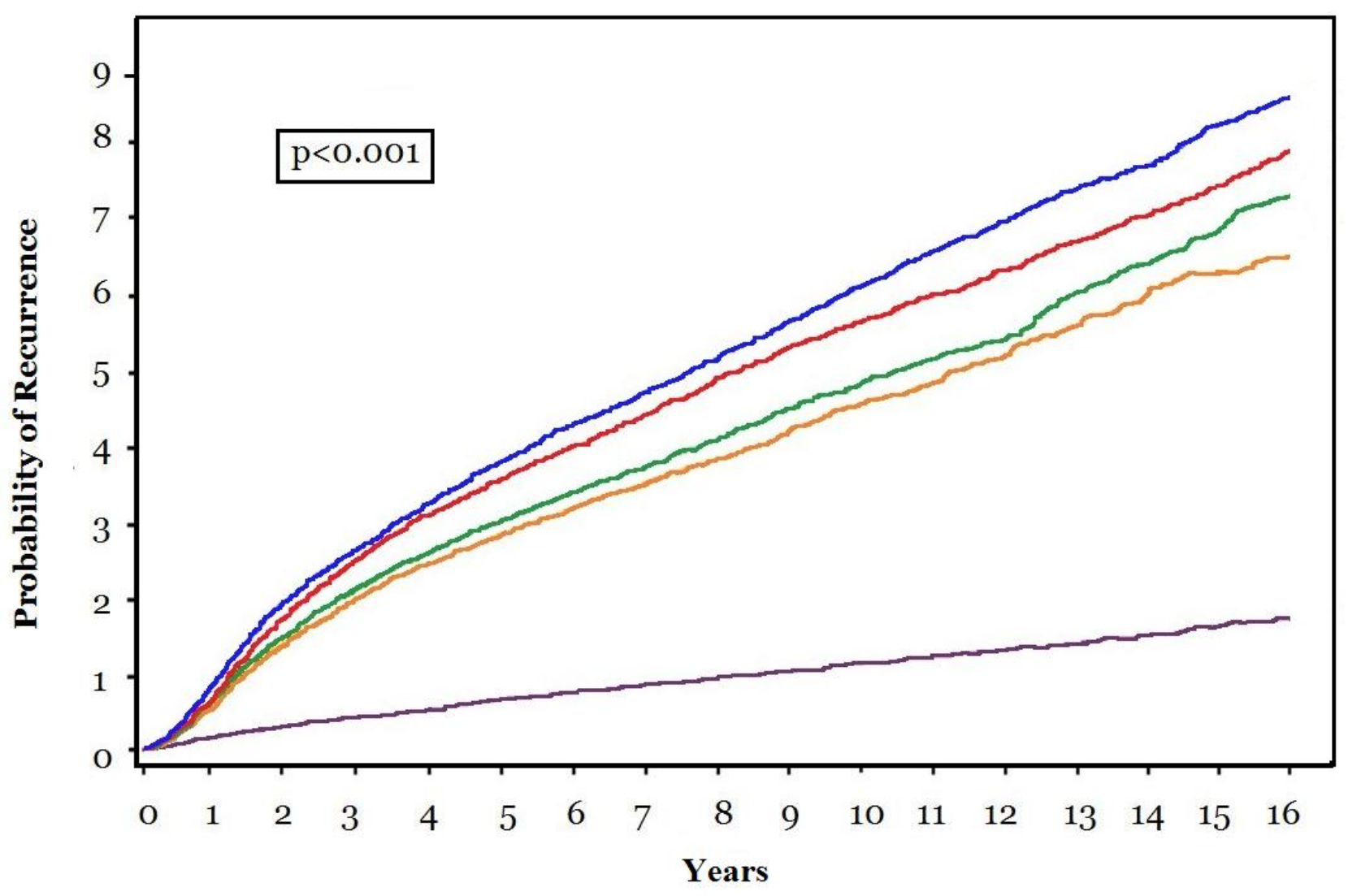


$\underline{\text { General Hospitals Divided into Terciles }}$

A second analysis was conducted using terciles to identify hospital volume categories instead of quartiles. Table 3.7 indicates that there were approximately an equal number of patients across general hospital terciles, and that the incidence rate was highest at lowest volume hospitals. The higher the volume of surgeries conducted, the lower the incidence rate was when comparing mid-volume and high-volume general hospitals. The most significant comparison however was the significantly lower incidence rate at Shouldice hospital when compared to the highest volume general hospitals (5.1 vs. 1.1$)$.

Table 3.7: General cohort characteristics based on hospital volume and type (Terciles)

\begin{tabular}{|c|c|c|c|c|c|}
\hline Hospital Category & $\begin{array}{c}\text { Lowest } \\
\text { Volume }\end{array}$ & $\begin{array}{c}\text { Mid } \\
\text { Volume }\end{array}$ & $\begin{array}{c}\text { Highest } \\
\text { Volume }\end{array}$ & Shouldice & Overall \\
\hline Number Of Patients & 57,029 & 56,481 & 56,555 & 65,127 & 235,192 \\
\hline Number of Recurrences & 2979 & 2725 & 2615 & 701 & 9020 \\
\hline Person-Years & 543,561 & 493,808 & 514,141 & 651,267 & $2,202,777$ \\
\hline Incidence Rate (/1000 & 5.48 & 5.52 & 5.09 & 1.08 & 4.09 \\
\hline PY) & $1-130$ & $131-231$ & $232-803$ & $5103-5888$ & - \\
\hline Volume Cut-Points & 5.22 & 4.82 & 4.62 & 1.08 & 3.84 \\
\hline Crude Recurrence (\%) & 5.35 & 5.08 & 4.95 & 1.15 & 3.95 \\
\hline Age-Standardized (\%) & & & & & \\
\hline
\end{tabular}


Time-to-event regression results are displayed in Table 3.8. This table indicates that when general hospital inguinal hernia patients are categorized into terciles instead of quartiles, the volume outcome trends are more consistent, as seen below. The hazard ratios indicate that highest volume general hospitals are associated with the best outcomes, followed by midvolume, and that lowest volume general hospitals are associated with the least beneficial patient outcomes. Again, none of the general hospital categories were able to match the benefit associated with treatment at Shouldice hospital.

Table 3.8: Risk of Hernia Recurrence by Hospital Volume and Type (Cox Regression - Terciles)

\begin{tabular}{|c|c|c|c|}
\hline \multicolumn{5}{|c|}{ Cox Regression* } \\
\hline Hospital Category & Hazard Ratio & $\mathbf{9 5 \%}$ CI & P-Value \\
\hline Lowest Volume & 1.00 & $(0.93-1.03)$ & 0.34 \\
\hline Mid Volume & 0.98 & $(0.86-0.96)$ & $<0.001$ \\
\hline Highest Volume & 0.91 & $(0.18-0.21)$ & $<0.001$ \\
\hline Shouldice & 0.19 & & \multicolumn{2}{|c|}{ (Referent) } \\
\hline
\end{tabular}

*Adjusted for: Age, Sex, Income Quintile, Comorbidity 
Figure 3.3: Probability of Recurrence By Hospital Volume (Terciles)

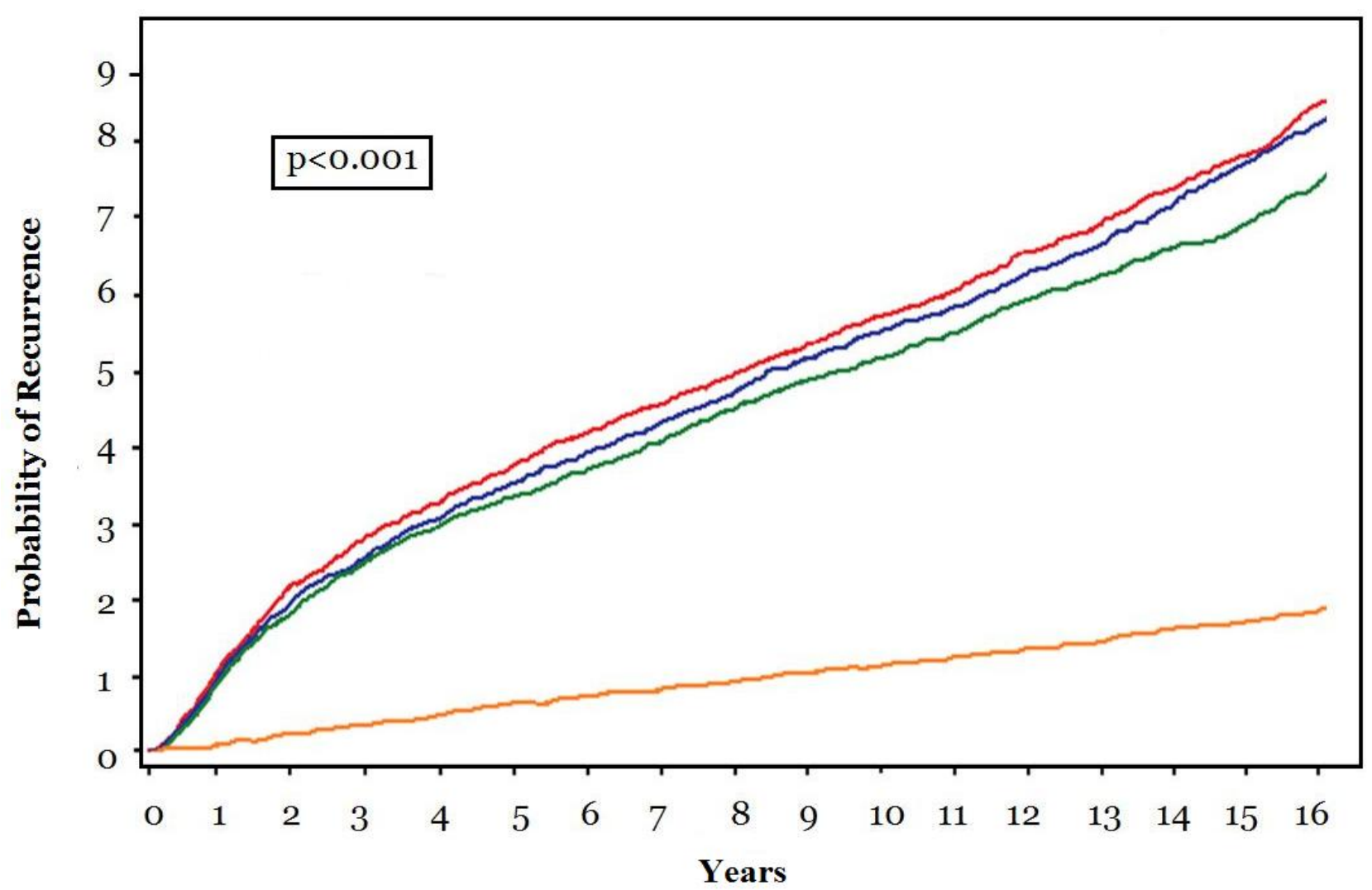

$\overline{\text { Lowest Vol. }} \overline{\text { Mid Vol. }} \overline{\text { Highest Vol. }} \overline{\text { Shouldice }}$

The Kaplan-Meier curves in Figure 3.3 indicate that lowest volume hospitals were associated with the greatest probability of recurrence, followed by mid-volume general hospitals, and that patients who had treatment at highest volume general hospitals did not have as high a risk of recurrence as other general hospital volume categories. The risk of recurrence after treatment at Shouldice Hospital however, was substantially lower than that observed within general hospital categories, including the highest volume general hospitals. 
Compared to the Kaplan-Meier curves in Figure 3.2 which indicate quartile analysis, it is apparent in Figure 3.4 above that the volume-outcome relationship is better displayed (that is, lowest volume perform worst, highest volume hospitals perform better in comparison) in general hospital volume categories when general hospital patients are divided into terciles instead of quartiles.

\section{5: ADDITIONAL ANALYSES}

\section{Sensitivity Analyses}

A sensitivity analysis was completed to compare outcomes amongst the healthiest patients in the cohort. Results for the sensitivity analysis are presented in Table 3.9. This sensitivity analysis revealed that even when comparing the healthiest patient population across general hospital categories and Shouldice, that Shouldice hospital is still associated with a significant benefit over treatment at general hospitals. 


\begin{tabular}{|c|c|c|c|}
\hline \multicolumn{5}{|c|}{ Table 3.9: Sensitivity Analysis -Cox Regression Limited to Healthy Patients } \\
\hline Hospital Category & Hazard Ratio & $\begin{array}{c}\text { 95\% Confidence } \\
\text { Interval }\end{array}$ & P-Value \\
\hline Lowest Volume & 1.00 & \multicolumn{2}{|c|}{ (Referent) } \\
\hline Mid-Low Volume & 1.13 & $(1.06-1.20)$ & $<0.001$ \\
\hline Mid-High Volume & 0.98 & $(0.92-1.05)$ & 0.59 \\
\hline Highest Volume & 0.92 & $(0.85-0.97)$ & 0.01 \\
\hline Shouldice & 0.19 & $(0.18-0.21)$ & $<0.001$ \\
\hline
\end{tabular}

Another sensitivity analysis was conducted to observe the effect of time period on the risk of recurrence; results for 2 different time periods (1993-2000 and 2001-2007) are displayed below in tables 3.10 and 3.11.

Table 3.10 indicates that while Shouldice Hospital performed significantly better than general hospital categories in the 1990s. This was the time during which newer repair techniques were being adopted at general hospitals across Ontario. 
Table 3.10: Sensitivity Analysis - Cox Regression (1993-2000)

\begin{tabular}{|c|c|c|c|}
\hline Hospital Category & Hazard Ratio & 95\% CI & \multicolumn{2}{|c|}{ P-Value } \\
\hline Lowest Volume & 1.00 & $(1.09-1.24)$ & $<0.001$ \\
\hline Mid-Low Volume & 1.17 & $(0.89-1.03)$ & 0.01 \\
\hline Mid-High Volume & 0.95 & $(0.85-0.98)$ & $<0.001$ \\
\hline Highest Volume & 0.91 & $(0.16-0.20)$ & \multirow{2}{|c|}{} \\
\hline Shouldice & 0.18 & \multicolumn{2}{|c|}{ (Refent) } \\
\hline
\end{tabular}

Table 3.11 indicates that in the later part of the study, while Shouldice hospital did perform better than general hospital categories, that the effect was not as strong as what was observed in the 1990s (hazard ratio of 0.18 in the 1990 s, vs. 0.28 in the 2000s).

Table 3.11: Sensitivity Analysis - Cox Regression (2001-2007)

\begin{tabular}{|c|c|c|c|}
\hline Hospital Category & Hazard Ratio & 95\% CI & P-Value \\
\hline Lowest Volume & 1.00 & $(0.95-1.22)$ & 0.25 \\
\hline Mid-Low Volume & 1.08 & $(0.99-1.26)$ & 0.08 \\
\hline Mid-High Volume & 1.11 & $(0.85-1.09)$ & 0.52 \\
\hline Highest Volume & 0.96 & $(0.24-0.33)$ & $<0.001$ \\
\hline Shouldice & 0.28 & & \\
\hline
\end{tabular}




\section{Stratified Analysis}

A forest plot showing risk of recurrence at Shouldice hospital vs. General hospitals in Ontario, stratified by covariate groups is displayed below in Figure 3.4. This forest plot indicates that Shouldice hospital performed better consistently when compared to general hospitals in Ontario, but that there were some sub-groups for which treatment at Shouldice hospital was associated with better outcomes.

Younger patients (age <55), of male gender, those who had treatment in the 1990s, came from high income households and had a low burden due to comorbidity, were more likely to benefit from treatment at Shouldice hospital. P-values which indicate a comparison across the variables show that several trends are significant. This suggests that different sub-populations may have better outcomes than others when treated at Shouldice hospital. 
Figure 3.4: Risk of Recurrence (Stratified by Groups)

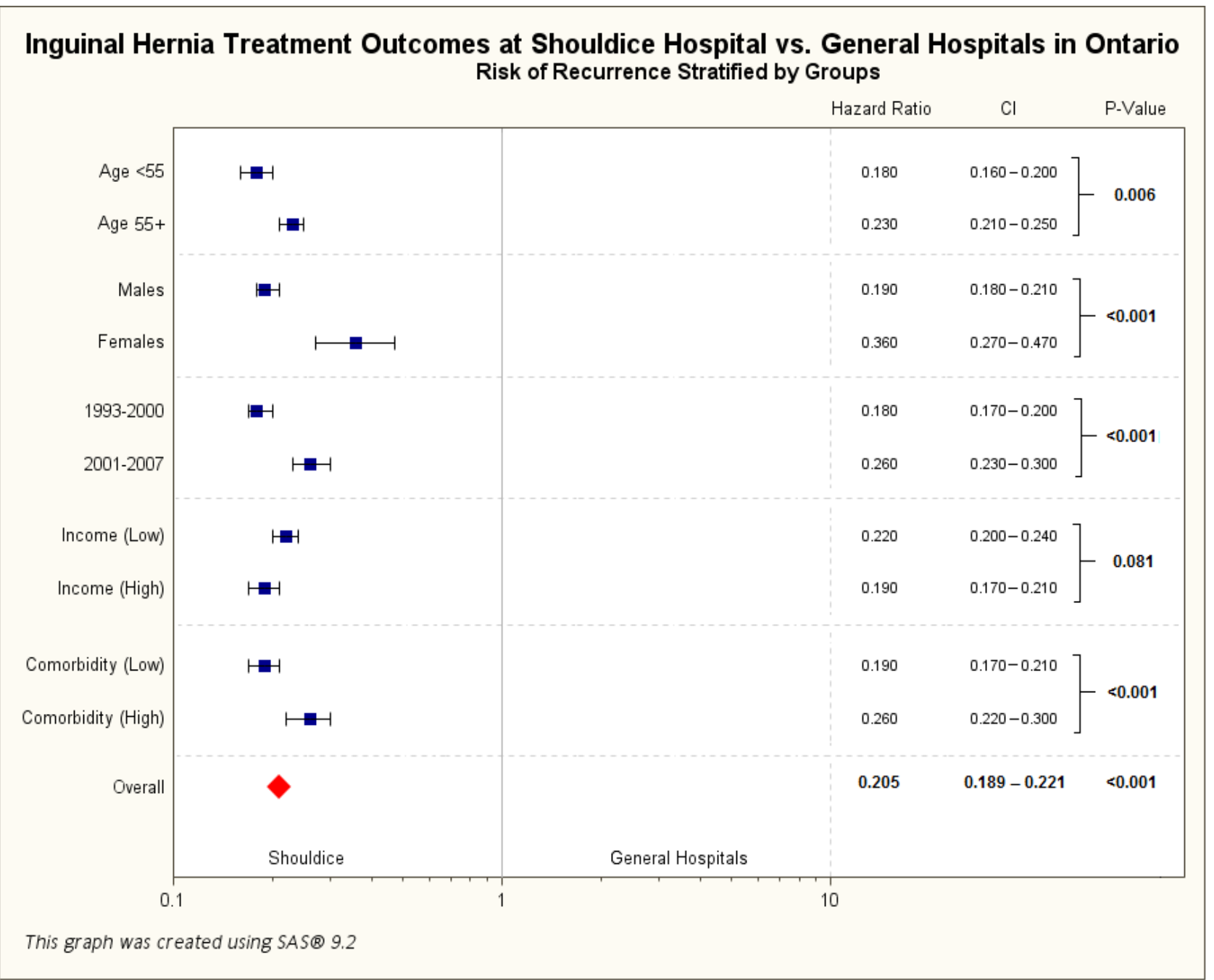

\section{Shouldice Hospital Patient Selection}

Lastly, an analysis was conducted to observe the effect of patient selection on hernia recurrence outcomes at Shouldice hospital vs. general hospitals in Ontario. This 2-year analysis revealed that of the approximately 6500 individuals who underwent initial consultation at Shouldice 
hospital between 2004-2006, $90 \%$ went on to have surgeries at Shouldice, vs. $10 \%$ who went on to receive treatment at general hospitals in Ontario or elsewhere.

\section{Outcomes at Teaching Hospitals}

17 teaching hospitals were identified via institutional information from CIHI-DAD. Majority of the patients who had treatment at teaching hospitals were classified as having treatment at a high volume hospital, which is consistent with common knowledge, as most teaching hospitals are larger facilities with higher patient volumes (Table 3.12).

Table 3.12: Distribution of Primary Inguinal Hernia Repair Patients in Ontario Teaching Hospitals

\begin{tabular}{|l|l|l|l|l|l|}
\hline $\begin{array}{l}\text { Teaching } \\
\text { Hospital } \\
\text { Volume }\end{array}$ & $\begin{array}{l}\text { Lowest } \\
\text { Volume }\end{array}$ & Mid-Low & Mid-High & Highest Volume & Total \\
\hline $\mathrm{N}(\%)$ & $112(5.3 \%)$ & $329(15.57)$ & $461(21.8 \%)$ & $1211(57.3 \%)$ & $2113(100 \%)$ \\
\hline
\end{tabular}

Treatment at a high volume teaching hospital however, was not associated with significantly better outcomes (that is, lower recurrence rates) when compared to lower volume teaching hospitals (as shown in Table 3.13). None of the P-values or confidence intervals in this analysis revealed a significant benefit associated with a specific type of teaching facility (note: Shouldice Hospital was not included in this analysis as it is not classified as a teaching facility). 


\begin{tabular}{|c|c|c|c|}
\hline \multicolumn{2}{|c|}{ Table 3.13: Risk of Hernia Recurrence at Ontario Teaching Hospitals } \\
\hline \multicolumn{3}{|c|}{ Cox Regression } \\
\hline Category & Hazard Ratio & $95 \%$ CI & P-Value \\
\hline Lowest Volume & 1.00 & \multicolumn{2}{|c|}{ (Referent) } \\
\hline Mid-Low Volume & 0.97 & $(0.78-1.21)$ & 0.787 \\
\hline Mid-High Volume & 1.03 & $(0.84-1.28)$ & 0.773 \\
\hline Highest Volume & 0.90 & $(0.73-1.09)$ & 0.269 \\
\hline
\end{tabular}




\section{CHAPTER 4: DISCUSSION AND CONCLUSIONS}

\section{1: THESIS SUMMARY}

A volume-outcome relationship has been discussed and documented numerous times in the medical literature (52); typically, the higher the volume of procedures completed, the better the outcomes are for patients. Although the trend demonstrated across quartiles in this study, which indicated increasingly beneficial outcomes with increasing hospital volume is consistent with past medical literature, the main theme of this study was to discover if high volume at a specialty hospital, such as Shouldice, provides patients with a significant benefit when compared to high volume at a general hospital.

\section{$\underline{\text { Recurrence Rates: }}$}

Using a dataset with full population coverage from a publicly funded health care system in Ontario, we demonstrated that indeed, there is a significant difference, since the risk of recurrence is $4.8 \%$ (95\% confidence interval: $4.5 \%$ to $5.0 \%$ ) at high volume general hospitals, which is significantly higher than $1.2 \%$ (95\% confidence interval: $1.1 \%$ to $1.3 \%$ ) at the Shouldice hospital. 
Recurrence rates at Shouldice Hospital have been reported to be low since the inception of this specialty hospital; however when the Shouldice technique is compared to other repair techniques, the recurrence rate using the Shouldice technique outside the Shouldice Hospital is reported to be between 5-8\% (85).

Shouldice Hospital reports that the $1 \%$ recurrence rate at Shouldice hospital is not just the result of the specialized surgical repair technique, or the surgical expertise, but rather that the Shouldice technique is more effective than other techniques when performed at an extremely high volume, as is done at Shouldice Hospital. This is why when the Shouldice technique was used at centers outside of Shouldice Hospital at low volumes, outcomes were not found to be as favourable as those observed at Shouldice Hospital.

\section{Time-to-Event Regression:}

Cox proportional hazards model indicated that even after adjusting for covariates that could potentially confound results, such as age, sex, income level, comorbidity, or year or index event, that the benefit of treatment at Shouldice Hospital was still significantly better than at general high volume hospitals (Shouldice vs. lowest volume quartile (reference) adjusted hazard ratio 0.20, (95\% CI 0.18 to 0.21$), \mathrm{P}<0.001$, compared to highest volume general hospital quartile vs. lowest volume quartile (reference) adjusted hazard ratio 0.90 (95\% CI 0.84 to 0.95 ), $\mathrm{P}<0.001$. 


\section{$\underline{\text { Kaplan-Meier Curves }}$}

The Kaplan-Meier curves indicating probability of recurrence over the time period of the study (1993-2007), as well as the hazard ratios obtained through cox regression modeling indicated that the lowest volume category performed better than the mid-low volume hospitals in the study. To observe the effect of classifying hospitals according to volume differently, patients who underwent surgery at general hospitals in Ontario were split into terciles instead of quartiles. The results of this analysis showed that lowest volume hospitals performed worse than midvolume hospitals, which is consistent with the widely known and expected relationship between volume and outcome. The reason why the mid-low and lowest volume curves were switched in the quartile based analysis may be due to the way in which volume is being defined within our study. The results from the tercile analysis show that this disparity was resolved when the hospital volume categories are defined differently, therefore indicating that the switched results from the quartile analysis are not a concerning finding.

\section{$\underline{\text { Sensitivity Analysis - Cohort Limited to Healthiest Patients }}$}

The results from the sensitivity analysis indicated that even when the healthiest patients are compared, Shouldice Hospital displays significantly better outcomes for patients undergoing inguinal hernia treatment. A common criticism for Shouldice Hospital is that it treats only the 
healthiest patients, leaving the more complicated cases for general hospitals. However, this sensitivity analyses shows that even when only the healthiest patients who are treated at general hospitals are compared to the presumably healthier population at Shouldice, that Shouldice still has significantly better outcomes for patients, indicating that the benefit of treatment there is to be attributed in part to reasons other than just their method of screening patients.

$\underline{\text { Sensitivity Analysis - Trend Variations according to Time Period }}$

The results of the second sensitivity analysis, which compared the effect of time period (1990s vs 2000s) on the risk of recurrence, showed that Shouldice recurrence rates were lower in the early period of our study (from 1993-2000), than in the later part of our study (2001-2007). Mesh hernia repair, as well as laparoscopic hernia repair gained wider attention and adaptation after 1998, and prior to this, other more conventional techniques at the time were preferred by most surgeons (32).

Thus, the results from this analysis indicate that the benefit associated with treatment at Shouldice Hospital was likely more in the past, when older repair techniques were used at general hospitals, and with the onset of mesh and other minimally invasive techniques, this benefit has slightly decreased (comparatively). 


\section{$\underline{\text { Stratified Analysis }}$}

However, if observing overall trends, as displayed in the stratified forest plot (Figure 3.4), one can elucidate that even though the benefit associated with treatment at Shouldice Hospital did diminish slightly in the later part of our study, that compared to general hospitals categories in Ontario, treatment at Shouldice hospital was still associated with a significant benefit overall (even in the 2000s).

The stratified analysis also showed that treatment at Shouldice Hospital was associated with a stronger benefit for those who are younger, those of male gender, as well as those who are from higher income households and have a low burden due to comorbidity. This suggests that

although overall trends indicate that Shouldice hospital performs better than general hospitals in Ontario, that there may be some patient types who may not benefit as strongly as a result of treatment at Shouldice.

\section{$\underline{\text { Patient Selection at Shouldice Hospital }}$}

Furthermore, an analysis which involved the identification of those patients who had initial consultations at Shouldice hospital, and then went on to have surgery at Shouldice vs. other hospitals, revealed that roughly $90 \%$ of those patients who are initially evaluated by a surgeon at 
Shouldice, do go on to have surgery at that center. The remaining $10 \%$, who may have been denied service at Shouldice hospital due to a variety of factors (lack of insurance/coverage, inappropriate medical history, smoking status etc), could go on to have surgery at general hospitals in Ontario.

This indicates that patient selection at Shouldice Hospital is not as severe as widely believed although it is true that Shouldice hospital does not operate on those who are smokers or on morbidly obese patients, the results from this study indicate that even if Shouldice Hospital performs on healthier patients, the outcomes observed (lower recurrence rates), are still extremely beneficial to the province from a patient outcome, and potentially also from a financial point of view.

Results from this study show that 65,127 individuals underwent elective primary inguinal hernia repair at Shouldice hospital over the study period. These individuals had a $1.1 \%$ risk of developing a recurrence, as compared to those who had their primary repairs at general hospitals in Ontario. The analysis of patient selection at Shouldice indicated that roughly $10 \%$ of individuals who initially had a consultation at Shouldice hospital, did not go on to have surgery there. These individuals may have been turned away due to various factors, or may have opted themselves to be treated at a general hospital. 
If we are to assume that these individuals were turned away as a result of severe comorbidities, or because they were "unfavourable" patients, as is often suggested by critics of Shouldice Hospital, a quick analysis can be performed to reveal what the likelihood of recurrence would have to be in these individuals, for Shouldice hospital to have the same recurrence as general hospitals. This calculation is explained in detail below.

Number of individuals treated at Shouldice hospital (roughly): 65,127

These 65,127 patients represent the $90 \%$ of cases with initial consultations at Shouldice, who also went on to have surgery there. The remaining $10 \%$ were patients who did have initial consultation but did not go on to have surgery at Shouldice.

Thus, we can calculate that the number of individuals who had initial consultation at Shouldice was: 72,363 , of which $10 \%$ had surgeries other than Shouldice: 7236 patients

If these 7236 individuals who are presumably high morbidity patients, also had surgery at Shouldice, the total approximate number of surgeries conducted at Shouldice would then be 72,363

Since we know that a $1.1 \%$ recurrence rate is observed in the 65,127 patients who had surgery at Shouldice (therefore 701 recurrences) and a $4.5 \%$ recurrence rate is observed at high volume general hospitals, we can calculate that 3256 recurrences would have had to occurred overall for 
the recurrence rate to be $4.5 \%$ at Shouldice (if the $10 \%$ who did not return had indeed proceeded with treatment at Shouldice).

Thus we are left with a final calculation, which is to find out what the recurrence rate would have to be in the $10 \%$ of patients who did not go on to have treatment at Shouldice; this calculation reveals that a $35 \%$ recurrence rate ((3256-701)/7236) among those 7236 individuals would be necessary to bring the recurrence rate at Shouldice hospital up to the level of high volume general hospitals (that is, from $1.1 \%$ to $4.5 \%$ ). The chances of such a high recurrence rate among this specific patient population is extremely low.

Furthermore, roughly $25 \%$ of patients at Shouldice were identified as having a high comorbidity burden, so the criticism received by Shouldice hospital for not treating more serious patients at all is also likely not true. It is important to recognize that while patient selection at Shouldice is a well known fact, it is not as severe and as selective for extremely healthy patients as widely believed.

$\underline{\text { Outcomes at Teaching Hospitals }}$

Analysis of patient outcomes for those individuals who had primary treatment at a teaching facility in Ontario, revealed that although most individuals who undergo treatment at a teaching 
facility are treated at a high volume teaching facility, there is no benefit associated with treatment at a high volume teaching facility vs. a lower volume teaching hospital.

Therefore, this indicates that typical volume outcome relationships may not apply to teaching facilities and that lower volume hospitals can perform at a rate comparable to higher volume general hospitals as a result of being a teaching facility (as this can have many associated benefits).

\section{2: IMPLICATIONS AND RECOMMENDATIONS}

\section{Clinical}

Since there is an obvious quality of care differential present across the different hospital categories, high volume centers may not need to modify their clinical practice since they generally experience outcomes that are acceptable. It is also likely that surgeons who work in high volume centers also observe acceptable outcomes, however it is unlikely that uniform outcomes would be observed across all surgeons. Therefore, if there is a process via which hospitals are able to audit their outcomes in order to identify surgeons who report poorer performance, and a system is put in place which would allow training of these surgeons, this may be a model of care that could lead to improved quality of care. 
Those surgeons who report poorer outcomes either at high volume centers as well as those at low volume hospitals, could contribute significantly towards improved patient outcomes. This could be accomplished if they are able to adjust their practices by adhering to the evidence-based publications that recommend practice guidelines, or by adjusting their individual techniques so that patients have a high likelihood of successful surgery.

\section{Methodological}

The primary methodological challenges of this thesis relate to the structure of the data that was used. There is clustering of patients observed at multiple levels, hence our data did not conform to the assumption of independent observations that is usually implicit in most regression analyses. Failure to account for this clustering at all levels of our analyses may have resulted in Type 1 error by decreasing the standard errors around our model parameter estimates. This would also have decreased the corresponding P-values $(86,87)$.

\section{Health Policy}

Shouldice Hospital being a "Center of Excellence" specialty surgical hospital, has been found to have a significantly lower recurrence rate through this study. The significant differences between Shouldice and high volume general hospitals indicate that the sole reason for lower recurrence 
rates may not be the higher volume of surgeries at Shouldice alone, rather other processes may be contributing to the significant disparity.

These may include the surgical technique (Shouldice technique at Shouldice Hospital vs. other techniques at general hospitals), the hospital stay at Shouldice Hospital or the special diet that patients are placed on, differences in staff expertise and finally perhaps also due to Shouldice Hospitals preference for treating non-complicated cases. The sheer number of cases performed by Shouldice surgeons likely also has an effect, due to surgical expertise being enhanced for the surgeons operating exclusively on hernias at Shouldice hospital, vs. those surgeons who work at general hospitals and may perform other surgeries in addition to hernia operations, thus reducing the number of hernia cases they take.

Even though it has been determined that treatment at Shouldice Hospital is associated with significantly better outcomes for patients in terms of recurrence rates, concentrating all resources in "centers of excellence" may not be practical, particularly for large sparsely populated areas such as some regions in Ontario.

From a health policy point of view, funding initiatives to further research aimed at understanding processes and structures of care important to inguinal hernia patients may help address this disparity between recurrence statistics. Finally, at least within the southwestern Ontario region 
where Shouldice Hospital is located, it may be recommended that primary care physicians refer more patients to Shouldice Hospital for surgery, as even if Shouldice Hospital is able to take on more simple cases, this would lead to more operating room availability at larger general hospitals which would have a positive effect on wait times for other general surgery procedures.

It is notable however that outcomes due to treatment at Shouldice Hospital are not just a result of using the Shouldice technique, so the adaptation of this technique by surgeons in smaller hospitals, or by surgeons who perform a very low volume of inguinal hernia surgeries may not be as effective, because this technique has to be used at very high volumes to result in an extremely low recurrence rate of roughly $1 \%$.

According to data from CIHI, the average cost of a hernia surgery (including hospital stay, staff salaries, equipment costs) is roughly $\$ 7000$ (88). This number does not include physician billing fees, so accounting for consultations, recurrent repair physician fees as well as hospital costs, it can be confirmed that high recurrence rates for hernia surgery cause an unnecessary burden in terms of health expenditure and also in terms of patient discomfort and lost productivity. With policy changes, it may be possible to avoid these deleterious effects of higher recurrence rates at general hospitals. Through a shift in referral practices, and through a better understanding of adaptable policies at Shouldice Hospital (by elucidating the processes of care there), thousands of hernia recurrences could be averted every year, which could potentially save the province substantial costs, and also result in better outcomes and quality of life for patients. 
This study has lent important evidence to the growing body of literature which suggests that specialty hospitals are essential to fulfill the needs of a rapidly growing and aging population. If specialized surgical centers such as Shouldice Hospital or the Cambie Surgery Centre in Vancouver (which is a private institution devoted exclusively to conducting surgical procedures of any type) are promoted and more such centers are created, this could result in better patient outcomes, reduced wait times, and greater quality of care overall.

\section{3: THESIS LIMITATIONS}

As with any research study, our study is not without limitations; one such limitation is the lack of information regarding bilateral hernias. Detailed information pertaining to the size of the hernia, repair method used, surgeon expertise or surgeon volume was also not available for the study; these are all factors which can affect the risk for a patient to develop a recurrence later on. The OHIP and CIHI DAD codes did not identify with certainty if the inguinal hernia repair was performed laparoscopically or via several other hernia repair methods.

At Shouldice Hospital the Shouldice repair method is used exclusively, but information for the various repair methods used at general hospitals was not available. This is a limitation to our 
research because depending on the type of repair method used, outcomes can vary greatly, as mentioned earlier (open vs. mesh vs. laparoscopic repair techniques) (89).

As mentioned previously, although a study was conducted in Ontario to evaluate surgeon preferences with regards to inguinal hernia repair technique (90), information from this research is very limited and currently outdated. Without similar research which is more recent, it is not possible to know how many surgeons in Ontario prefer to use older techniques, and how many now use mesh or minimally invasive techniques. We defined "recurrence" as a surgical repair for recurrence, and this may not have captured all recurrences; however it is unlikely that these cases would differ between the different hospital volume categories.

Furthermore, information on obesity was not accurate, and morbid obesity is an obvious risk factor for recurrent hernias. Due to lack of reliable data, this could not be accounted for in the study, albeit the number of morbidly obese patients would presumably be small. We also were unable to find out which surgeries were conducted under general anesthesia vs. local anesthesia, however it is known that most surgeries performed at Shouldice are under local anesthesia. Comorbidity scores were used as a surrogate to account for severity of the patient's case, and although is not the best measure of how serious a certain hernia repair is, or how likely the patient is to recur, it is still a useful indicator. Furthermore, there is a certain level of error associated with administrative data which cannot be ignored, however statistical tests as outlined in previous sections were used optimally to reduce the effect of any such error. 
Information was also not available to account for the bilateral nature of hernias, which is a limitation of our research. For instance, if an individual had a hernia repair on their right side, and several years later also had one on their opposite side, and then a recurrence occurred in one of the two and was repaired, we were unable to know via billing codes which side the recurrence occurred. However, bilateral hernias only occur in a certain percentage (roughly 20\%) of patients, and differences with regards to this between general hospitals and Shouldice would not be expected to be substantial enough to threaten the validity of our competitive analyses.

Lastly, a major limitation of our research was the inability to account for patient selection factors at Shouldice in detail; Shouldice hospital is known for turning away certain patients who do not comply with pre-set guidelines (non-smokers, must be below a certain BMI threshold). Critics may argue that since this has not been controlled for, that recurrence rates at Shouldice hospital are artificially low as they choose the most beneficial patients. It may also be possible that other general hospitals do not detect very small hernias well or decide not to operate on very small hernias and instead surgeons recommend that the hernia be tracked over time to see if it worsens. This would also make the Shouldice recurrence rate seem lower than it would be if this was not possible.

While our results have shown that this is not true, since patient selection at Shouldice is not significant enough to cause such a huge variation in recurrence rates, it is also important to 
recognize that this does occur at Shouldice hospital and that this was not accounted for in our study. Further research would be required to discover what the precise impact of such selection factors is on recurrence rates (as discussed below in detail).

\section{4: FUTURE STUDIES}

Future studies could include an in depth cost-effectiveness evaluation study; such research could be beneficial for health policy purposes as it could model potential cost savings to be gained by increasing referrals to Shouldice Hospital, where patients would have better outcomes, fewer recurrences, fewer QALYs (quality-adjusted life years) lost, and therefore potentially millions of dollars saved for the government. An evaluation of the repair methods preferred by surgeons across Ontario, and linking this information to surgeon expertise and outcomes could also be beneficial to learn more about volume outcome hernia relationships at the surgeon/provider level (91).

This study revealed that there is a significant benefit associated with treatment at Shouldice hospital when compared to general hospitals in Ontario; it was not possible however, to evaluate the various factors which may have contributed to this variation. To better understand why there is such a variation in recurrence rates between this specialty surgical hospital and general hospitals, further research is required to evaluate the process of care at Shouldice hospital. This will allow the results from this research to be better understood. 
Although our brief analysis to observe the effect of patient selection factors at Shouldice Hospital did reveal that patient selection at Shouldice hospital is not as significant as widely believed, it is necessary to conduct more research into this matter to elucidate what the precise methods are for evaluating patients at Shouldice hospital, and if patient selection involves simply turning away patients, or if it mostly involves educating and rehabilitating patients prior to their surgery. If it is the latter, this is something that perhaps can be applied even in the general hospital scenario, however this is subject to time and resource constraints.

\section{5: CONCLUSIONS}

Special expertise in surgical procedures can improve surgical outcomes. Specialty hospitals focus on treating a single condition. It is unclear if inguinal hernia treatment at a high volume specialty hospital can result in improved patient outcomes compared to high volume general hospitals.

The purpose of this study was to compare hernia recurrence rates in patients undergoing primary elective inguinal hernia repair at general hospitals with a high volume hernia specialty center (the Shouldice Hospital in Ontario, Canada). The result of this large population-based cohort study was that persons who had elective primary inguinal hernia repair at the Shouldice Hospital had a substantially lower risk of recurrence than those who had surgery at general hospitals, including high volume general hospitals. 


\section{REFERENCES}

1. Turnage RH, Richardson KA, Li BD, McDonald JC. Abdominal wall, umbilicus, peritoneum, mesenteries, omentum, and retroperitoneum. In: Townsend CM, Beauchamp RD, Evers BM, Mattox KL, eds. Sabiston Textbook of Surgery. 18th ed. Philadelphia, Pa: Saunders Elsevier;2008:chap 43.

2. Sherwinter DA, Gupta A, Eckstein JG. Natural orifice translumenal endoscopic surgery inguinal hernia repair: A survival canine model. J Laparoendosc Adv Surg Tech A. 2011 Apr;21(3):209-13.

3. Kingsnorth AN, LeBlanc KA. Management of abdominal hernias. 3rd ed. London, New York: Edward Arnold; 2003:40-47.

4. Primatesta P, Goldacre MJ. Inguinal hernia repair: Incidence of elective and emergency surgery, readmission and mortality. Int J Epidemiol. 1996 Aug;25(4):835-9.

5. Fitzgibbons RJ Jr, Hurder-Giobbie A, Gibbs JO, et al. Watchful waiting vs. repair of inguinal hernia in minimally symptomatic men. A randomized clinical trial. JAMA 2006;295:285-92.

6. Goroll AH, Mulley AG. Primary care medicine: office evaluation and management of the adult patient, 5th ed. Philadelphia, Lippincott Williams \& Wilkins; 2005:431-434.

7. Society for Surgery of the Alimentary Tract (2006). SSAT patient care guidelines: Surgical repair of groin hernias. Available online: http://www.ssat.com/cgibin/hernia6.cgi. 
8. Bax T, Sheppard BC, Crass RA. Surgical options in the management of groin hernias. Am Fam Physician. 1999 Jan 1;59(1):143-56.

9. Rutkow IM, Robbins AW. Classification systems and groin hernias. Surg Clin North Am. 1998 Dec;78(6):1117,27, viii.

10. Nyhus LM, Klein MS, Rogers FB. Inguinal hernia. Curr Probl Surg 1991; 28:418.

11. Nyhus LM. Classification of groin hernia: Milestones. Hernia. 2004 May;8(2):87-8.

12. Ruhl CE, Everhart JE. Risk factors for inguinal hernia among adults in the US population. Am J Epidemiol. 2007 May 15;165(10):1154-61.

13. van Wessem KJ, Simons MP, Plaisier PW, Lange JF. The etiology of indirect inguinal hernias: Congenital and/or acquired? Hernia. 2003 Jun;7(2):76-9.

14. Sorensen LT, Hemmingsen UB, Kirkeby LT, Kallehave F, Jorgensen LN. Smoking is a risk factor for incisional hernia. Arch Surg. 2005 Feb;140(2):119-23.

15. Sorensen LT, Friis E, Jorgensen T, Vennits B, Andersen BR, Rasmussen GI, et al. Smoking is a risk factor for recurrence of groin hernia. World J Surg. 2002 Apr;26(4):397-400.

16. Ijzermans JN, de Wilt H, Hop WC, Jeekel H. Recurrent inguinal hernia treated by classical hernioplasty. Arch Surg. 1991 Sep;126(9):1097-100.

17. Paul A, Troidl H, Williams JI, Rixen D, Langen R. Randomized trial of modified bassini versus shouldice inguinal hernia repair. the cologne hernia study group. Br J Surg. 1994 Oct;81(10):1531-4.

18. Gilbert AI, Graham MF, Voigt WJ. A bilayer patch device for inguinal hernia repair. Hernia 1999; 3:161-166. 
19. Hair A, Paterson C, Wright D, Baxter JN, O'Dwyer PJ. What effect does the duration of an inguinal hernia have on patient symptoms? J Am Coll Surg. 2001 Aug;193(2):125-9.

20. Gallegos NC, Dawson J, Jarvis M, Hobsley M. Risk of strangulation in groin hernias. Br J Surg. 1991 Oct;78(10):1171-3.

21. Awad SS, Fagan SP. Current approaches to inguinal hernia repair. Am J Surg. 2004 Dec;188(6A Suppl):9S-16S.

22. Liem MS, van der Graaf Y, van Steensel CJ, Boelhouwer RU, Clevers GJ, Meijer WS, et al. Comparison of conventional anterior surgery and laparoscopic surgery for inguinalhernia repair. N Engl J Med. 1997 May 29;336(22):1541-7.

23. Glassow F. Inguinal hernia repair. A comparison of the shouldice and cooper ligament repair of the posterior inguinal wall. Am J Surg. 1976 Mar;131(3):306-11.

24. Lichtenstein IL, Shulman AG, Amid PK, Montllor MM. The tension-free hernioplasty. Am J Surg. 1989 Feb;157(2):188-93.

25. Amid PK. Lichtenstein tension-free hernioplasty: Its inception, evolution, and principles. Hernia. 2004 Feb;8(1):1-7.

26. Taylor SG, O'Dwyer PJ. Chronic groin sepsis following tension-free inguinal hernioplasty. Br J Surg. 1999 Apr;86(4):562-5.

27. Neumayer L, Giobbie-Hurder A, Jonasson O, Fitzgibbons R,Jr, Dunlop D, Gibbs J, et al. Open mesh versus laparoscopic mesh repair of inguinal hernia. N Engl J Med. 2004 Apr $29 ; 350(18): 1819-27$.

28. McKernan JB, Laws HL. Laparoscopic repair of inguinal hernias using a totally extraperitoneal prosthetic approach. Surg Endosc. 1993 Jan-Feb;7(1):26-8. 
29. McCormack K, Wake BL, Fraser C, Vale L, Perez J, Grant A. Transabdominal preperitoneal (TAPP) versus totally extraperitoneal (TEP) laparoscopic techniques for inguinal hernia repair: A systematic review. Hernia. 2005 May;9(2):109-14.

30. Liem MS, van Steensel CJ, Boelhouwer RU, Weidema WF, Clevers GJ, Meijer WS, et al. The learning curve for totally extraperitoneal laparoscopic inguinal hernia repair. Am J Surg. 1996 Feb;171(2):281-5.

31. Beattie GC, Kumar S, Nixon SJ. Laparoscopic total extraperitoneal hernia repair: Mesh fixation is unnecessary. J Laparoendosc Adv Surg Tech A. 2000 Apr;10(2):71-3.

32. Ferzli GS, Frezza EE, Pecoraro AM,Jr, Ahern KD. Prospective randomized study of stapled versus unstapled mesh in a laparoscopic preperitoneal inguinal hernia repair. J Am Coll Surg. 1999 May;188(5):461-5.

33. Novik B, Hagedorn S, Mork UB, Dahlin K, Skullman S, Dalenback J. Fibrin glue for securing the mesh in laparoscopic totally extraperitoneal inguinal hernia repair: A study with a 40-month prospective follow-up period. Surg Endosc. 2006 Mar;20(3):462-7.

34. Park A, Birch DW, Lovrics P. Laparoscopic and open incisional hernia repair: A comparison study. Surgery. 1998 Oct;124(4):816,21; discussion 821-2.

35. Beets GL, Dirksen CD, Go PM, Geisler FE, Baeten CG, Kootstra G. Open or laparoscopic preperitoneal mesh repair for recurrent inguinal hernia? A randomized controlled trial. Surg Endosc. 1999 Apr;13(4):323-7.

36. Bageacu S, Blanc P, Breton C, Gonzales M, Porcheron J, Chabert M, et al. Laparoscopic repair of incisional hernia: A retrospective study of 159 patients. Surg Endosc. 2002 Feb;16(2):345-8. 
37. Chan CK, Chan G. The Shouldice technique for the treatment of inguinal hernia. J Min Access Surg 2006;2:124-8

38. "Shouldice Hospital." Hernia Hospital. Web. 1 Dec. 2011. <http://www.shouldice.com/>.

39. Rutkow IM. The recurrence rate in hernia surgery. How important is it? Arch Surg. $1995 ; 130: 575-6$.

40. Payne JH Jr, Grininger LM, Izawa MT, Podoll EF, Lindahl PJ, Balfour J. Laparoscopic or open inguinal herniorrhaphy? A randomized prospective trial. Arch Surg. 1994;129:973-9.

41. Ijzermans JN, de Wilt H, Hop WC, Jeekel H. Recurrent inguinal hernia treated by classical hernioplasty. Arch Surg. 1991;126:1097-100.

42. Fitzgibbons RJ Jr, Camps J, Cornet DA, Nguyen NX, Litke BS, Annibali R, et al. Laparoscopic inguinal herniorrhaphy. Results of a multicenter trial. Ann Surg. 1995;221:1-13.

43. Liem MS, van Graaf Y, van Steensel CJ, Boelhouwer RU, Clevers GJ, Meijer WS, et al. Comparison of conventional anterior surgery and laparoscopic surgery for inguinalhernia repair. N Engl J Med. 1997;336:1541-7.

44. Amid PK, Shulman AG, Lichtenstein IL. Local anesthesia for inguinal hernia repair stepby-step procedure. Ann Surg. 1994 Dec;220(6):735-7.

45. Sandbichler P, Draxl H, Gstir H, Fuchs H, Furtschegger A, Egender G, et al. Laparoscopic repair of recurrent inguinal hernias. Am J Surg. 1996 Mar;171(3):366-8. 
46. Amato B, Moja L, Panico S, Persico G, Rispoli C, Rocco N, et al. Shouldice technique versus other open techniques for inguinal hernia repair. Cochrane Database Syst Rev. 2009 Oct 7;(4)(4):CD001543.

47. McCormack K, Scott NW, Go PM, Ross S, Grant AM, EU Hernia Trialists Collaboration. Laparoscopic techniques versus open techniques for inguinal hernia repair. Cochrane Database Syst Rev. 2003;(1)(1):CD001785.

48. Birkmeyer JD, Siewers AE, Finlayson EVA, Stukel TA, Lucas FL, Batista I, Welch HG, Wennberg . Hospital Volume and Surgical Mortality in the United States. New England Journal of Medicine in 2002; 346:1128. Birkmeyer et al. Hospital Volume and Surgical Mortality New England Journal of Medicine in 2002.

49. Jollis JG, Romano PS. Volume-outcome relationship in acute myocardial infarction: The balloon and the needle. JAMA. 2000 Dec 27;284(24):3169-71.

50. Schrag D, Panageas KS, Riedel E, Hsieh L, Bach PB, Guillem JG, et al. Surgeon volume compared to hospital volume as a predictor of outcome following primary colon cancer resection. J Surg Oncol. 2003 Jun;83(2):68,78; discussion 78-9.

51. Birkmeyer JD, Stukel TA, Siewers AE, Goodney PP, Wennberg DE, Lucas FL. Surgeon volume and operative mortality in the United States. N Engl J Med 2003;349:2117-2127.

52. Shahian DM, Normand SL. The volume-outcome relationship: From luft to leapfrog. Ann Thorac Surg. 2003 Mar;75(3):1048-58.

53. Bach PB, Cramer LD, Schrag D, Downey RJ, Gelfand SE, Begg CB. The influence of hospital volume on survival after resection for lung cancer. N Engl J Med. 2001 Jul 19;345(3):181-8. 
54. Shactman, D. Specialty hospitals, ambulatory surgery centers, and general hospitals: Charting a wise public policy course. Health Affairs, 2005; 24(3): 868-373.

55. Satiani, B. Specialty hospitals: Who do they help? Surgery, 2008; 143:589-598.

56. Blackstone, E. A., \& Fuhr, J. P. Specialty hospitals: The economics and policy issues they pose. J Health Care Finance, 2007: 34(2): 1-9.

57. Tynan, A., November, E., Lauer, J., Pham, H. H., \& Cram, P. General hospitals, specialty hospitals and financially vulnerable patients. Center for Studying Health System Change, 2009; Research Brief, 11.

58. Bhandari, A., Dratler, S., Raube, K., \& Thulasiraj, R. D. Specialty care systems: A pioneering vision for global health. Health Affairs, 2008: 27(4), 964-976.

59. Carey, K., Burgess, J. F., Jr., \& Young, G. J. Specialty and full-service hospitals: A comparative cost analysis. HSR: Health Services Research, 2008; 43(5), Part II: 18691887.

60. Voelker R. Specialty hospitals generate revenue and controversy. JAMA. 2003 Jan 2229;289(4):409-10.

61. Winslow ER, Quasebarth M, Brunt LM. Perioperative outcomes and complications of open vs laparoscopic extraperitoneal inguinal hernia repair in a mature surgical practice. Surg Endosc. 2004 Feb;18(2):221-7.

62. Jansen PL, Klinge U, Jansen M, Junge K. Risk factors for early recurrence after inguinal hernia repair. BMC Surg. 2009 Dec 9;9:18.

63. Ijzermans JN, de Wilt H, Hop WC, Jeekel H. Recurrent inguinal hernia treated by classical hernioplasty. Arch Surg. 1991;126:1097-100. 
64. Madura JA, Madura JA,2nd, Copper CM, Worth RM. Inguinal neurectomy for inguinal nerve entrapment: An experience with 100 patients. Am J Surg. 2005 Mar;189(3):283-7.

65. Holmes J, Readman R. A study of wound infections following inguinal hernia repair. J Hosp Infect. 1994 Oct;28(2):153-6.

66. Callesen T, Bech K, Kehlet H. Prospective study of chronic pain after groin hernia repair. Br J Surg. 1999 Dec;86(12):1528-31.

67. Kehlet H. Chronic pain after groin hernia repair. Br J Surg. 2008 Feb;95(2):135-6.

68. Canonico S, Sciaudone G, Pacifico F, Santoriello A. Inguinal hernia repair in patients with coagulation problems: Prevention of postoperative bleeding with human fibrin glue. Surgery. 1999 Mar;125(3):315-7.

69. Mincheff T, Bannister B, Zubel P. Focal testicular infarction from laparoscopic inguinal hernia repair. JSLS. 2002 Jul-Sep;6(3):211-3.

70. Berger D, Bientzle M, Muller A. Postoperative complications after laparoscopic incisional hernia repair. incidence and treatment. Surg Endosc. 2002 Dec;16(12):1720-3.

71. Ministry of Health and Long-Term Care (2012). Public Information: Hospitals. Available online: http://www.health.gov.on.ca/english/public/contact/hosp/hosp_mn.html

72. Welsh DR, Alexander MA. The Shouldice repair. Surg Clin North Am. 1993;73:45169.

73. Wantz GE. The Canadian repair: Personal observations. World J Surg 1989;13:516-21.

74. Shouldice EB. The shouldice repair for groin hernias. Surg Clin North Am. 2003 Oct;83(5):1163,87, vii. 
75. Chan CK, Chan G. The Shouldice technique for the treatment of inguinal hernia. J Min Access Surg 2006;2:124-8

76. Glassow F. Short-stay surgery (shouldice technique) for repair of inguinal hernia. Ann R Coll Surg Engl. 1976 Mar;58(2):133-9.

77. Glassow F. The shouldice hospital technique. Int Surg. 1986 Jul-Sep;71(3):148-53.

78. Hawker GA, Coyte PC, Wright JG, Paul JE and Bombardier C: Accuracy of administrative data for assessing outcomes after knee replacement surgery. J Clin Epidemiol 1997; 50: 265.

79. Institute for Clinical Evaluative Sciences. Appendix - A summary of studies on the quality of Health Care Administrative Databases in Canada. ICES Practice Atlas 1996; 339.

80. Austin PC, van Walraven C, Wodchis WP, Newman A, Anderson GM. Using the johns hopkins aggregated diagnosis groups (ADGs) to predict mortality in a general adult population cohort in ontario, canada. Med Care. 2011 Oct;49(10):932-9.

81. Carlsson L, Borjesson U, Edgren L. Patient based 'burden-of-illness' in swedish primary health care. applying the johns hopkins ACG case-mix system in a retrospective study of electronic patient records. Int J Health Plann Manage. 2002 Jul-Sep;17(3):269-82.

82. Hosmer DW and Lemeshow S: Applied Logistic Regression. New York: J Wiley 2000.

83. Cox, D. R. Regression Models and Life Tables (with Discussion). Journal of the Royal Statistical Society, Series B 1972; 34:187-220.

84. Cox, D. R. \& D. Oakes. Analysis of Survival Data. London: Chapman and Hall.1984. 
85. Arvidsson D, Berndsen FH, Larsson LG, Leijonmarck CE, Rimback G, Rudberg C, et al. Randomized clinical trial comparing 5-year recurrence rate after laparoscopic versus shouldice repair of primary inguinal hernia. Br J Surg. 2005 Sep;92(9):1085-91.

86. Ying G and Liu C: Statistical analysis of clustered data using SAS system, 2006. Accessed October 20, 2011

(URL: http://www.nesug.org/proceedings/nesug06/an/da01.pdf).

87. Chuang SK, Tian L, Wei LJ and Dodson TB: Kaplan-Meier analysis of dental implant survival: a strategy for estimating survival with clustered observations. J Dent Res 2001; 80: 2016.

88. Canadian Institute for Health Information. The cost of acute care hospital stays by medical condition in Canada. Available online: https://secure.cihi.ca/free_products/nhex_acutecare07_e.pdf

89. Schmedt CG, Sauerland S, Bittner R. Comparison of endoscopic procedures vs lichtenstein and other open mesh techniques for inguinal hernia repair: A meta-analysis of randomized controlled trials. Surg Endosc. 2005 Feb;19(2):188-99.

90. DesCôteaux, J, Sutherland, F. Inguinal hernia repair: a survey of Canadian practice patterns. Can J Surg 1999;42:127-32.

91. Bocchi P. Shouldice's operation: Can results in a general surgical unit be the same as those in a highly specialized surgical unit? J Chir (Paris) 1993;130:275-7. 